\title{
Will a rising sea sink some estuarine wetland ecosystems?
}

\author{
S.E. Grenfell, R.M. Callaway, M.C. Grenfell, C.M. Bertelli, A.F. Mendzil and I. Tew
}

\section{Graphical abstract}
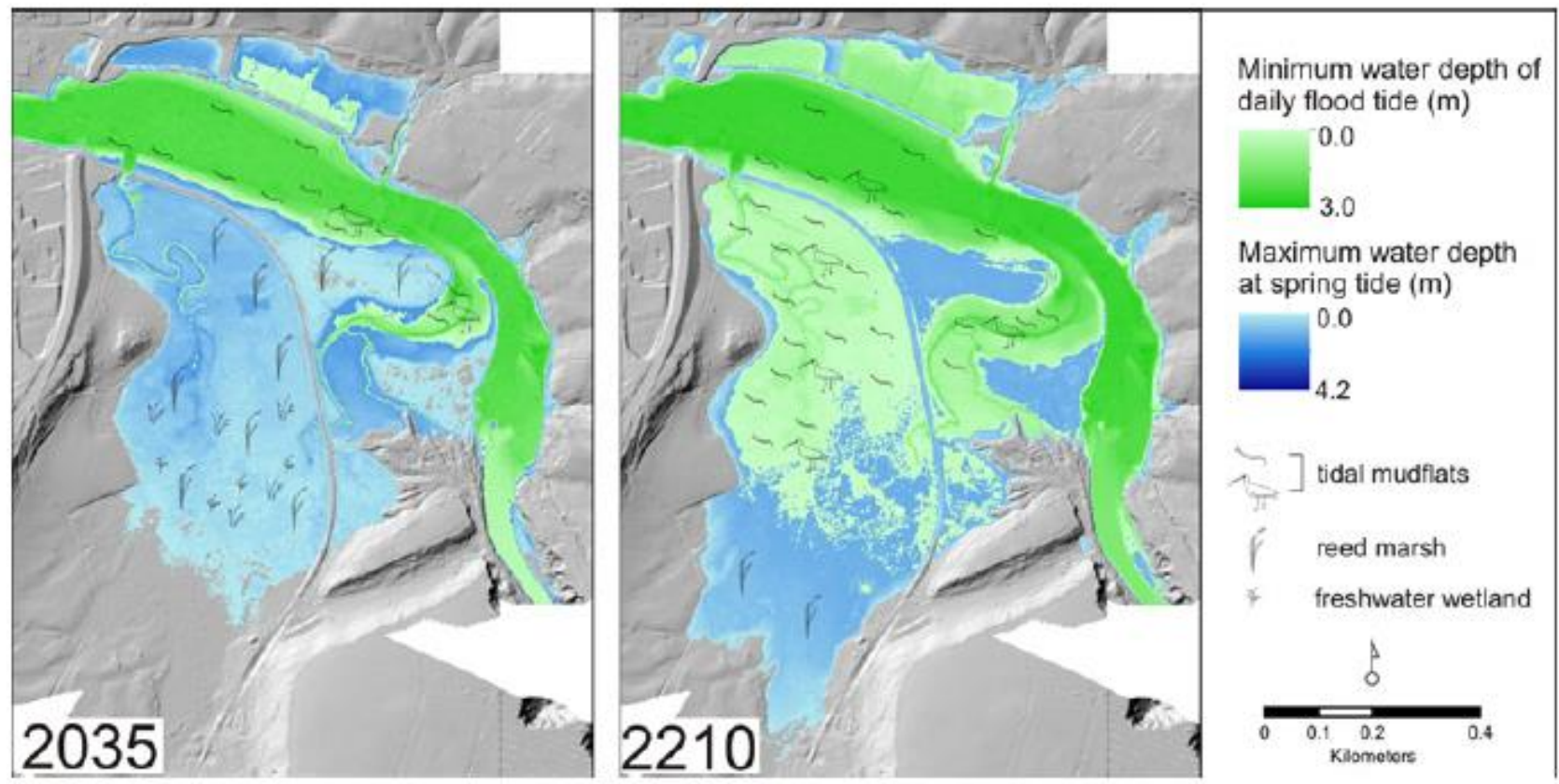

\begin{abstract}
Sea-level rise associated with climate change presents a major challenge to plant diversity and ecosystem service provision in coastal wetlands. In this study, we investigate the effect of sea-level rise on benthos, vegetation, and ecosystem diversity in a tidal wetland in west Wales, the UK. Present relationships between plant communities and environmental variables were investigated through 50 plots at which vegetation (species and coverage), hydrological (surface or groundwater depth, conductivity) and soil (matrix chroma, presence or absence of mottles, organic content, particle size) data were collected. Benthic communities were sampled at intervals along a continuum from saline to freshwater. To ascertain future changes to the wetlands' hydrology, a GIS-based empirical model was developed. Using a LiDAR derived land surface, the relative effect of peat accumulation and rising sea levels were modelled over 200 years to determine how frequently portions of the wetland will be inundated by mean sea level,
\end{abstract}


mean high water spring and mean high water neap conditions. The model takes into account changing extents of peat accumulation as hydrological conditions alter. Model results show that changes to the wetland hydrology will initially be slow. However, changes in frequency and extent of inundation reach a tipping point 125 to 175 years from 2010 due to the extremely low slope of the wetland. From then onwards, large portions of the wetland become flooded at every flood tide and saltwater intrusion becomes more common. This will result in a reduction in marsh biodiversity with plant communities switching toward less diverse and occasionally monospecific communities that are more salt tolerant. While the loss of tidal freshwater wetland is in line with global predictions, simulations suggest that in the Teifi marshes the loss will be slow at first, but then rapid. While there will be a decrease in biodiversity, the model indicated that at least for one ecosystem service, carbon storage, there is potential for an increase in the near future.

\section{Introduction}

Climate change and associated sea level rise is one of the greatest challenges to the continued provision of coastal wetland ecosystem services and biodiversity. Nicholls et al. (1999) estimate that by the 2080's, sea level rise could cause the loss of $22 \%$ of the world's coastal wetlands. The spatial impact of rising water levels on coastal wetlands has been the focus of numerous studies (e.g. Rogers et al., 2012; Poulter and Halpin, 2008; and others) which have highlighted the need to allow space for ecosystem migration inland. In many instances though, coastal squeeze will prevent ecosystem migration and the remaining wetland communities will be dramatically altered. In this study we use a two stepped approach to forecast what wetland vegetation communities might be like in a wetland in west Wales as sea level rises. First, we investigate controls on present wetland vegetation communities. Second, we model the effect of sea level rise on inundation levels in the wetland. We combine these analyses to provide a forecast of probable change in the distribution of wetland vegetation communities over the next 200 years.

Predicting change to wetland ecosystems is complex as alterations to the physical environment are mediated by biological interactions, often resulting in an outcome that is not necessarily obvious (Day et al., 2008). Nevertheless, by studying systems in which a single environmental variable has been altered, it may be possible to understand trajectories of change in similar ecosystems while acknowledging the cascading effect that change may have on other environmental variables. Warren and Niering (1993) applied this method to the New England saltmarshes in the US, by contrasting current vegetation with a survey completed in 1947. In our study, we investigate existing environmental gradients within the wetland and use these to evaluate future changes to vegetation communities. This method, employing ergodic reasoning (space for time substitution), provides an alternative where long term data sets are absent. 
Likely scenarios were provided by raster based modelling of future inundation levels in the wetland against a background of ongoing organic sediment accumulation. Raster modelling is limited by the resolution of elevation data (e.g. Poulter and Halpin, 2008), but as Rogers et al. (2012) demonstrate, LiDAR elevation data provides a major advance in mapping coastal flooding. In their study, inundation levels were forecast by mapping rising sea levels onto a LiDAR digital elevation model to which an accretion model had been applied. The authors contrasted their work with 'bathtub' modelling (e.g. planar water surface flood inundation modelling, Priestnall et al., 2000), which fails to account for the increase in elevation of coastal wetlands through processes of mineral or organic accretion. More complex models include the effects of compaction and decomposition in addition to sediment accretion and incorporate feedbacks that may alter elevation (e.g. Day et al., 1999).

Using a combination of these methods, several authors have demonstrated the importance of ongoing sedimentation to coastal wetland resilience as sea levels rise. In most instances, research has shown that at IPCC best estimate rates, sedimentation in coastal wetlands is unable to keep pace with sea level rise (e.g. Day et al., 1999; van Wijnen and van Wijnen and Bakker, 2001; Goor et al., 2003; FitzGerald et al., 2008). Even when the feedback between inundation and vegetation growth is modelled, maintaining an equilibrium elevation is impossible in most coastal marshes (Kirwan and Temmerman, 2009). Resilience is particularly low in wetlands where changes in elevation are controlled by peat accumulation rather than clastic sedimentation. For example, in the wetlands of the Albemarle-Pamlico peninsula of North Carolina in the US, vertical accretion rates are considered too low to prevent submergence if sea level rise accelerates (Moorhead and Brinson, 1995).

In contrast, in areas where suspended sediment concentrations are high or increasing, some coastal wetlands may be able to persist (e.g. Temmerman et al., 2004; Reed, 2002; Morris et al., 2002). In San Francisco Bay for instance, marsh accretion as a result of sedimentation and peat formation has been able to compensate for high rates of subsidence and the low rate of sea level rise, maintaining the elevation of the marsh surface above mean high water (Patrick and DeLaune, 1990). A key factor is that the system is not sediment limited. Indeed, it has been suggested that sediment dispersal by natural and/or engineered mechanisms could mitigate coastal wetland loss in some of the World's largest deltas (Nittrouer et al., 2012; Edmonds, 2012).

This study is focussed on a small tidal wetland in west Wales that is located at the present day interface of fresh and salt water. The aim was to understand how inundation frequency and magnitude will alter as sea levels rise, and to evaluate the likely effect on vegetation and benthos communities. There is a regional need for insight into the potential for coastal wetlands to provide habitat and/or 
maintain their biodiversity such that wetland bird and animal populations can be sustained in the future. To develop this insight, we investigated present day benthos and vegetation along environmental gradients (i.e. wetness and salt tolerance). We then used a raster based model to estimate inundation levels at mean water level as well as at neap and spring tides. The model incorporated an accretion model to account for elevation that was continually created as peat was formed. The model accounted for an increase in peat formation extent as more of the wetland became flooded.

\subsection{The Pentood and Rosehill Marshes, Teifi Marsh}

The Teifi Marsh is located alongside a tidal estuarine stretch of the Teifi River just upstream of Cardigan town in west Wales, the UK (Fig. 1) and falls within a reserve managed by the Wildlife Trust of South and West Wales. The reserve comprises two marsh areas - the Rosehill Marsh on the eastern side of the abandoned CardiBach railway, and the Pentood marsh on the western side. A meandering stream, the Afon Piliau, drains a small catchment to the southwest ( $\sim 14 \mathrm{~km}^{2}$ in size), and flows through the Pentood Marsh into the Teifi River.

The reserve is managed for waterfowl habitat and is grazed by a combination of horses and water buffalo to encourage plant diversity. In addition, some ponds have been dug and are occasionally cleared to maintain patches of open water. The abandoned Cardi-Bach railway compartmentalises the marsh into two systems that vary hydrologically and ecologically (Fig. 1). The Rosehill Marsh, confined on all sides by a combination of the railway, an old slate tip and the Teifi River, is primarily reed bed. It receives some water from discontinuous channel networks that drain the Pentood Marsh and pass under the railway through culverts and also experiences tidally induced flooding from the Teifi River estuary. Contrarily, the Pentood Marsh has a restricted connection to the Teifi River at the junction of the Afon Piliau and the extent of tidally induced flooding is less pronounced than in the Rosehill Marsh.

Prior to the last glaciation, the Teifi River occupied a wide meandering floodplain. During the Last Glacial Maximum, Irish Sea ice reached the west coast of Wales creating ice dammed lakes in coastal river valleys across western Wales. One of the largest was Llyn Teifi (Fletcher and Siddle, 1998). During the glaciation, the lake and the pre-existing course of the Teifi River were gradually filled with glaciallyderived sediment. 


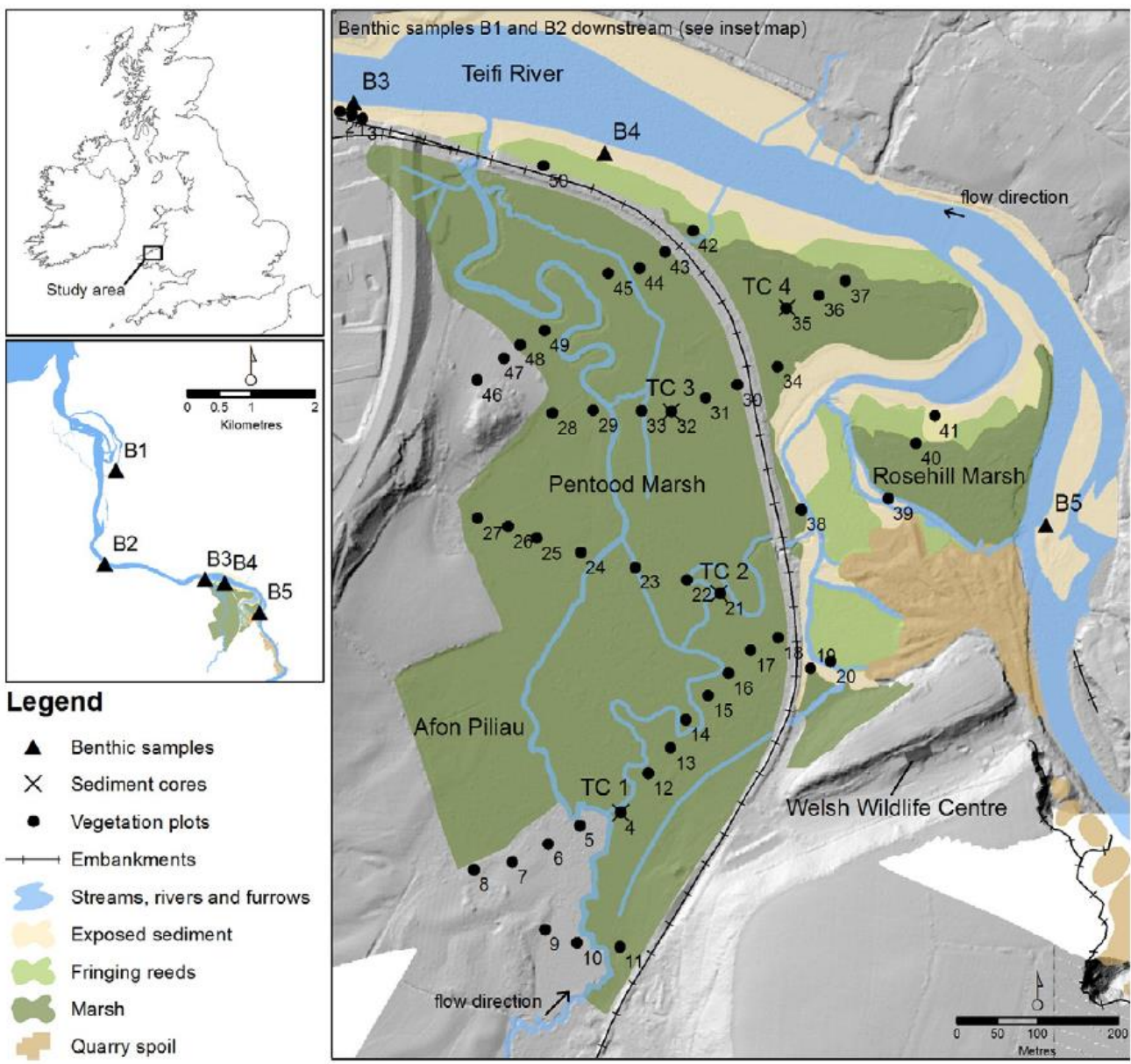

Fig. 1. Location of benthic sampling positions, vegetation plots and sediment cores. Fringing reeds and marsh vegetation types are digitised from the 1953 Ordnance Survey map. Pentood and Rosehill Marshes are approximately $5 \mathrm{~km}$ upstream of the Teifi River mouth.

Retreat of the sea ice as the climate warmed resulted in catastrophic dam bursts and the erosion of deep gorges at Cilgerran and Cenarth (Glasser et al., 2004). The current Teifi River flows through these gorges, and large portions of the old meandering course have been abandoned (Allen, 1960). The Teifi Marshes are located on one of the most prominent of these abandoned meanders, which have been shown to be filled with up to $30 \mathrm{~m}$ of sediment (Allen, 1960). The hydrological base level of the valley is set by the River Teifi, which has allowed the development of the Teifi palustrine wetlands (similar to those described by Grenfell et al., 2010). Current rates of minerogenic sedimentation within the marsh are negligible allowing the accumulation of peat.

\section{Methods}

\subsection{Field data collection}

During late August 2012, 50 sample plots were located across the wetland to capture variation in vegetation, hydrology and sedimentology (Fig. 1). At each plot, vegetation was identified and coverage estimated using the Braun-Blanquet scale. In herbaceous wetland vegetation, plots had a radius of $2 \mathrm{~m}\left(12.5 \mathrm{~m}^{2}\right)$ while in woodland areas a plot radius of $5 \mathrm{~m}\left(78.5 \mathrm{~m}^{2}\right)$ was used. At each plot, a surface 
sediment sample was taken and a small hole cored to measure ground- and/or surface water conductivity using a WTW Multi 340i conductivity meter. Depth to groundwater or depth of surface inundation was measured using an Eijkelkamp sounding device. In addition to surface sediment samples, four sedimentological cores were taken and logged in the field using a combination of a Russian peat corer and Eijkelkamp auger set. Core $\mathrm{TC} 4$ was transported to the laboratory for sub-sampling, whereas TC1, 2 and 3 were sub-sampled in the field at $0.5 \mathrm{~m}$ intervals or more frequently through sections of sedimentological change. The position and elevation of all vegetation plots and sediment cores was surveyed using a Leica Viva GNSS Netrover which provided sub-centimetre accuracy in $\mathrm{x}, \mathrm{y}$ and z co-ordinates.

To determine the composition of the benthic invertebrate flora, additional sediment core samples were taken along the intertidal shores of the Teifi Estuary. Sampling was conducted at five sites along the estuary and river, ranging from the tidal mudflats bordering the marsh to a location $4 \mathrm{~km}$ seaward of the Teifi Marsh.

At each site six replicate samples were taken covering a surface area of $100 \mathrm{~cm}^{2}, 15$ $\mathrm{cm}$ deep. Surface sediment samples were taken from the top $5 \mathrm{~cm}$ using a trowel. Surface water temperature, salinity and $\mathrm{pH}$ were measured at the sampling sites on 24/08/2012 during high water.

\subsection{Laboratory analysis}

Particle size distribution and organic content was determined for all surface and core sediment samples. For particle size determination, organics were removed from 1 to $2 \mathrm{~g}$ of sample by pre-treating with concentrated hydrogen peroxide overnight, followed by heating to complete the reaction. The prepared samples were then analysed in a Malvern Mastersizer 2000, which employs laser diffraction methods to measure particle size, using a manual wet dispersion unit. Organic content was calculated by incinerating known sample masses in a furnace

for $4 \mathrm{~h}$ at $45 \mathrm{O}^{\circ} \mathrm{C}$. Three peat samples from core TC4 were sent to Beta Analytic Inc. in Miami, Florida for radiocarbon dating by AMS.

The benthos samples were washed through a $0.5 \mathrm{~mm}$ mesh sieve, and the sieve remains were analysed for invertebrates. The fauna was identified to species level and counted.

\subsection{Data analysis}

2.3.1 Two-way indicator species analysis (TWINSPAN) of vegetation

WinTWINS 2.3 (Hill and Šmilauer, 2005), a windows based version of the original TWINSPAN software, was used to develop a community based classification of the wetland vegetation. In TWINSPAN, sample plots are classified first followed by a species classification, producing a succinct two-way table that may be interpreted to identify vegetation communities. Classification is conducted using a series of 
ordinations (correspondence analyses), that systematically divide the samples into two groups to create a dichotomous hierarchy. Species abundance is accounted for by 'pseudospecies'. Division continues until a user-defined criterion is reached. In many cases, TWINSPAN may be used to identify environmental variables that have an impact on vegetation distribution (e.g. soil wetness). One of the main criticisms of TWINSPAN is that dichotomies do not usually exist in nature, resulting in inaccurate final classifications (Jongman et al., 1995). Nevertheless, interpreted with care, TWINSPAN provides a useful method of analysing large vegetation data sets.

\subsubsection{Benthic infauna analyses of intertidal mudflats}

Differences in the composition of the benthic infauna communities between the five sampling sites along the Teifi estuary were tested with a permutation multivariate analysis of variance (PERMANOVA), based on Bray-Curtis dissimilarity of $\log (x+1)$-transformed abundance data (Anderson et al., 2008). The relationship between communities is illustrated by non-metric multidimensional scaling (MDS) (Clarke and Warwick, 2001).

The relationship between the benthic community and environmental predictor variables was analysed and modelled by distance-based linear models (DISTLM) and illustrated by distance-based redundancy analysis (dbRDA) (Anderson et al., 2008). Benthic communities were represented by Bray-Curtis dissimilarity of $\log (\mathrm{x}+1)$-transformed abundances after summing abundance information from the 6 individual cores of each site, and they were linked to predictor variables '\%sand', '\% clay and silt', 'distance from mouth of estuary (m)', 'temperature $\left({ }^{\circ} \mathrm{C}\right)$ ' and $\log (\mathrm{x}+1)$ salinity (ppt)'. Correlations between predictor variables were explored by Draftman plot (Anderson et al., 2008), which revealed significant correlations between 'distance to mouth of estuary' and 'salinity' and 'temperature'. Hence only the factors 'distance to mouth of estuary', '\%sand' and '\% clay and silt' were entered in the model.

\subsubsection{Development of the empirical sea level rise and peat accretion model}

In order to investigate the impact of rising sea levels on hydrology and vegetation, a GIS-based empirical model was developed. Using a starting land surface, the relative effect of peat accumulation and rising sea levels are modelled over time to determine which areas are likely to be inundated by mean sea level, mean high water spring and mean high water neap conditions. The model takes into account that as hydrological conditions alter due to changes in sea level, the spatial extent of peat accumulation will expand and/or contract, impacting upon organic accretion.

For simplicity, the model assumes peat accumulation occurs at a constant rate that is not spatially variable. The structure of the model allows the user to adjust inundation levels, accretion rates or the length of the time step. If mineral sediment accretion was important, it would be possible to incorporate these calculations into the existing model. 
2.3.3.1 Model data inputs. Starting surface elevation was provided by an Aerial LiDAR (Light Detecting and Ranging) Digital Terrain Model (DTM) supplied by the Environment Agency, UK.

Environment Agency DTM's are 'bare earth' elevation models that have been filtered to remove buildings, vehicles and vegetation, and thus provide a clear base for flood inundation analyses. The spatial resolution of the DTM was $1 \mathrm{~m}$ with a vertical accuracy between 5 and $15 \mathrm{~cm}$.

The rate of peat accretion was calculated using radiocarbon dates from core TC4. A linear regression $\left(\mathrm{R}^{2}=0.911\right)$ comparing depth and age suggested a time averaged accretion rate of $0.87 \mathrm{~mm} \cdot \mathrm{a}^{-1}$. Since the accretion rate at a particular position is likely to be variable over time, the rate, averaged over $\sim 4000$ years, provides a suitable estimate of likely accretion rates across the wetland. Furthermore, the rate also includes the effect of compaction, negating the need for additional compression calculations in the model.

Forecasts of sea level were based on estimates derived for the UK Climate Impacts Program (UKCIP, 2010) which were originally based on simulations from 16 MultiModel Ensembles (MME) using a medium emissions scenario. These were compared to Met Office results derived using Perturbed Physics Ensembles (PPE). The range of values from the MME simulations was greater, and so these were used so that a larger scale of uncertainty could be represented. The resulting MME estimates, which account for sea-level rise associated with both thermal expansion and melting of land ice, were then corrected for vertical land movement (Bradley et al., 2009; Milne et al., 2006; Shennan et al., 2006). In the long-term, the UKCIP high estimate forecast sea level for Cardiff is similar to that calculated from a linear projection of current sea level rise measured at Milford Haven (Hakin gauge, Permanent Service for Mean Sea Level, PSMSL, 2013; Woodworth and Player, 2003). However, all UKCIP estimates are higher in the long term compared to estimates from rates of current sea level rise at Fishguard and Newlyn, primarily because they are linear rather than polynomial projections (Fig. 2).

In order to ensure compatibility with the LiDAR dataset, UKCIP estimates were corrected to account for the difference between the UKCIP baseline (mean sea level between 1980 and 1999) and Ordnance Datum Newlyn (based on mean sea level between 1915 and 1921 inclusive, measured at Newlyn). For estimates of inundation during Mean High Water Neap (MHWN) and Mean High Water Spring (MHWS), forecast estimates were used in combination with the current MHWN and MHWS values as provided by the Proudman Oceanographic Laboratory software (POLTIPS, 2013), corrected for AOD Newlyn. 


\subsubsection{Basic model steps.}

1. Depth of peat accreted between model iterations is calculated.

The amount of peat accreted is dependent on the length of the time step (between 10 and 25 years for this study), the accretion rate and the spatial extent considered hydrologically suitable for peat formation (Fig. 3). For the first time step, the extent of peat accumulation mapped in the field is used as the spatial input. In subsequent iterations, the output from step 4 is used so that changing hydrological conditions affecting the formation of peat are taken into account.

2. Peat accreted is added to LiDAR DTM to calculate forecast DTM

For each time step, land surface elevation is predicted using the output from step 1 combined with an existing DTM. For the first time step, the original LiDAR data set is used. In subsequent iterations, the output from the preceding iteration is used as an input. In the Pentood and Rosehill Marsh, minerogenic sedimentation is negligible and is excluded from calculations.

3. Forecast DTM is compared to forecast sea level elevation

The forecast land surface elevation is compared to the forecast sea level elevation, inundated pixels are extracted.

4. Relationship between sea level and depth of inundation used to forecast spatial extent of peat accretion for next iteration 


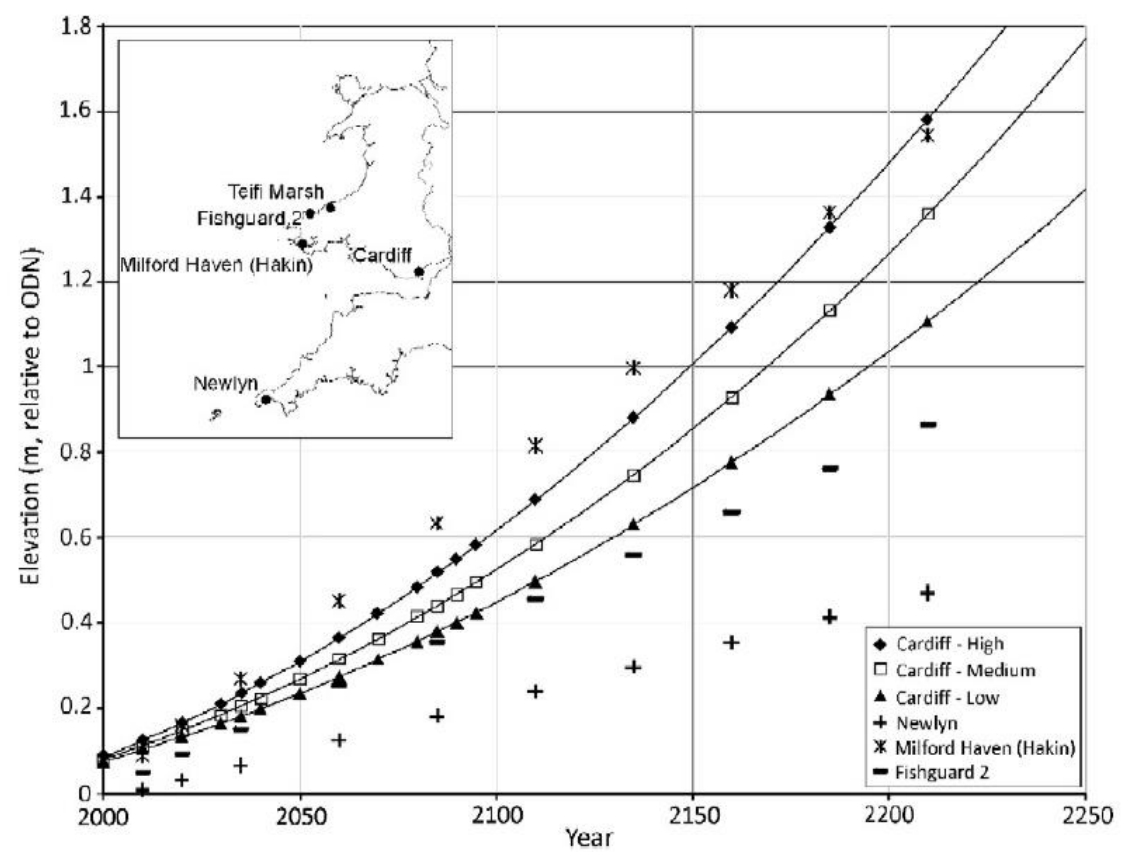

Fig. 2. A comparison of UKCIP derived sea level forecast estimates for Cardiff (UKCIP, 2010) and an extrapolation of measured rates of sea level rise at Newlyn, Fishguard and Milford Haven (Permanent Service for Mean Sea Level, PSMSL, 2013; Woodworth and Player, 2003). All records are relative to Ordnance Datum Newlyn.

The major peat forming plant in the Teifi wetlands is the reed Phragmites australis. In Britain, $\mathrm{P}$. australis may occur where the water table is between $1 \mathrm{~m}$ below and $1 \mathrm{~m}$ above ground level (Haslam, 1972). Expansion of the reed bed is primarily through the production of vegetative rhizomes, which may allow colonization of relatively deep water. As temperature increases, the depth of water that may be colonised increases, with water depths up to $4 \mathrm{~m}$ colonised in tropical regions (Haslam, 1972).

An analysis of current peat extent and elevation determined from LiDAR data was used to estimate the extent of future conditions suitable for peat formation. Currently, 95.4\% of mapped peat occurred in wave- and scour-protected areas between -1 and $2.73 \mathrm{~m}$ amsl. The relationship between mean sea level and elevation indirectly accounts for the combined effect of base level (the Teifi River and mean sea level) and water inputs from the Afon Piliau catchment on wetland hydrology. Future extents are based on the assumption that the slope of the water table will be maintained as mean sea level rises (Fig. 3).

\section{Results}

\subsection{Description of current wetland and estuary status}

\subsubsection{Vegetation}

An interpretation of the TWINSPAN outputs identifies 10 wetland plant communities within the marshes (Fig. 4). The first division separates communities dominated by reeds and those dominated by rushes and herbs, with Phragmites australis and Phalaris arundinacea indicator species for Group 2 and Agrostis stolonifera, Juncus effusus and Persicaria hydropiper indicator species for 
Group 3. Separation between groups 4 and 5 is based on the occurrence of Phragmites australis, while Bolboschoenus maritimus is the indicator species for separation into groups 6 and 7.

Reed beds dominate the northern portions of the Pentood marsh, with the most dominant community (85) comprising mono-specific stands of Phragmites australis with nettles occurring on the reed bed margins. More diverse communities of reeds were also found, some with creeping herbs (e.g. 84), and one comprising a mixture of bulrush and reed (e.g. 11). In community 20, occupying most of the non-woodland portion of Rosehill Marsh, the reed bed was characterised by several ruderal species suggesting recent disturbance or environmental change.

The southern portion of Pentood Marsh is more diverse, with a mixture of wet woodland and meadow (4), semi-permanent marsh (24) and seasonal to permanent marsh dominated by creeping herbs and rushes (25). Toward the Teifi River, plant communities are often characterised by the occurrence of salt tolerant oraches and/or Bolboschoenus maritimus (e.g. 7 and 43).

Salt and moisture tolerance for each plot was calculated using Ellenberg values from the Online Atlas of the British and Irish Flora (2013). For each vegetation plot, the percentage of plant species combined with the degree of tolerance was used to create a single score. There is strong variation between communities based on the moisture and salt tolerance of vegetation in each. Community 43, occurring in a restricted area adjacent to the junction of the Afon Piliau and the Teifi River is the most salt and moisture tolerant, while communities 85 and 7 are also relatively salt tolerant. In contrast, the least salt and moisture tolerant communities are 4 and 13 .

\subsubsection{Sediment, hydrology and geomorphology}

The organic content of surface sediment increases from south to north across the wetland. In the south, even where soil hydroperiods (defined by soil matrix chroma data) indicate a high degree of wetness, organic contents remain relatively low. Furthermore, organic contents appear to be enhanced along the eastern edge of the Cardi-bach railway. This suggests that peat accumulation may be controlled by the occurrence of a depression in which peat can accumulate without disturbance. 


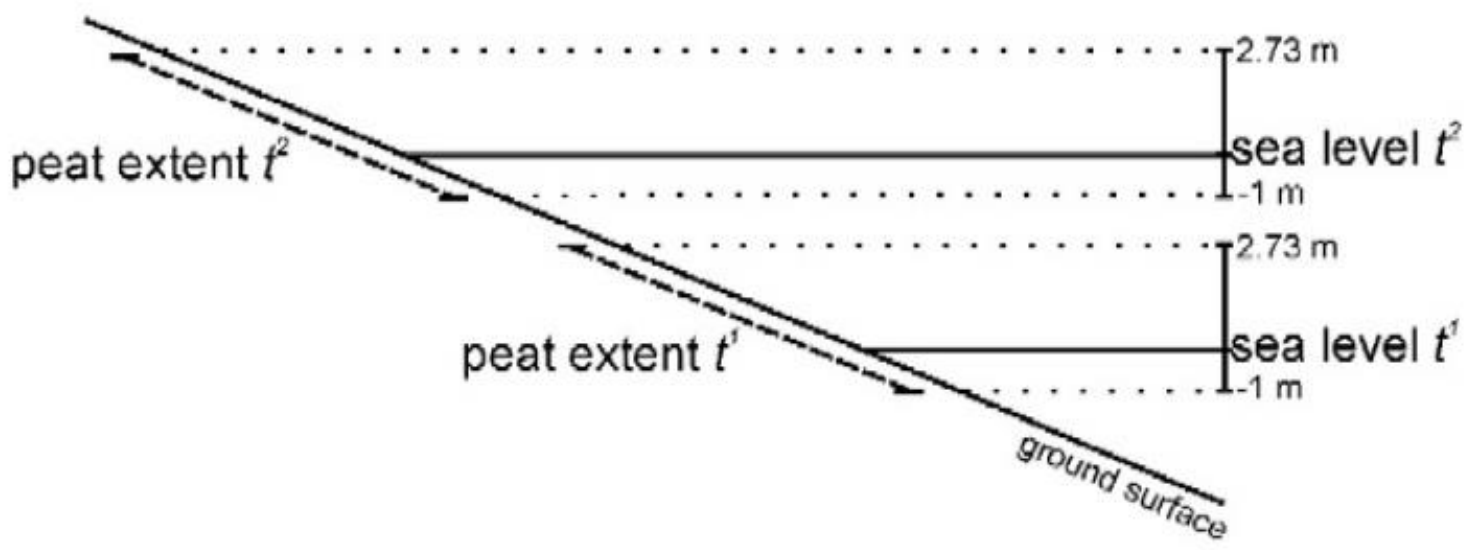

Fig. 3. The effect of rising sea level on forecast peat extent when water table slope is assumed to remain constant. 


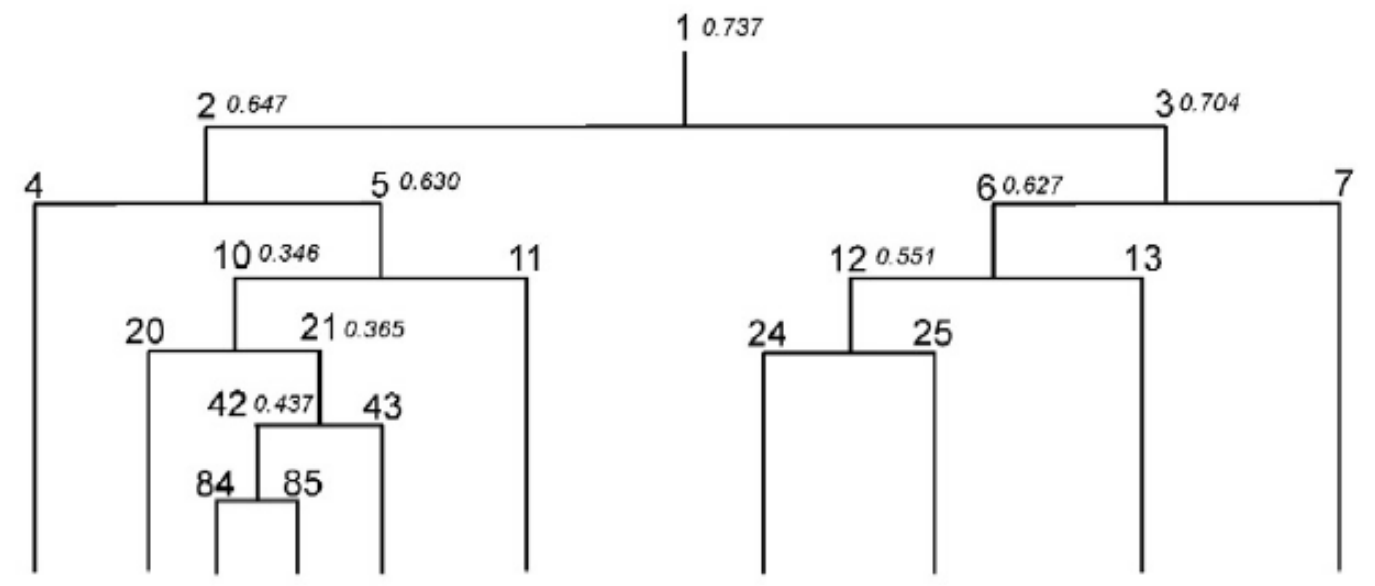

4 Wet hawthorn, willow and oak woodland (Crataegus monogyna, Salix cinerea and Quercus sp.) with Cock's foot (Dactylus glomerata) and Yorkshire Fog (Holcus lanata) meadow

20 Phragmites australis reedbed with terrestrial ruderals - hedge bindweed (Calystegia sepium) and hemp agrinomy (Eupatorium cannabinum)

84 Phragmites australis reedbed with creeping wetland herbs - water mint (Mentha aquatica), gypsy wort (Lycopus europaeus) and hemlock water drop-wort (Oenathe crocata)

85 Monospecific stands of Phragmites australis with nettles (Urtica dioica) on reed bed margins

43 Mixed herb (Agrostis stolonifera) and reed (Phragmites australis) marsh with minor Bolboschoenus maritimus

11 Mixed bulrush (Typha latifolia) and reed (Phragmites australis) marsh with creeping water mint (Mentha aquatica), gypsy wort (Lycopus europaeus) and Phalaris arundinacea

24 Soft rush (Juncus effusus), marsh ragwort (Senecio aquaticus) and willowherb marsh

25 Creeping herb (Agrostis stolonifera) and rush (Juncus effusus) permanent marsh with water pepper (Persicaria hydropiper), Skullcap (Scutelleria galericulata) and common water-starwort (Callitriche stagnalis)

7 Disturbed salt tolerant marsh with common orache (Atriplex patula) and Bolboschoenus maritimus

13 Wet grassland with plantains (Plantago major and Plantago lanceolata), the herb Yorkshire fog (Holcus lanatus) and daisy (Bellis perennis)

Fig. 4. Plot-based TWINSPAN vegetation classification. Eigenvalues for each split are shown in italics.

Surface sediments are coarser toward the north, and finer toward the south along the Afon Piliau. Sediments in Rosehill Marsh tended to be slightly coarser than those of Pentood Marsh, suggesting that the Teifi River may occasionally deposit sediment in the Rosehill Marsh. In contrast, the Pentood Marsh is protected from deposition from the Teifi River by the railway embankment.

Sediment cores indicate that organic accumulation is relatively recent across most of the Pentood Marsh, with high organic contents generally restricted to the top $10 \mathrm{~cm}$. Toward the Teifi River, organic contents usually exceeded $20 \%$ up to depths of $3.5 \mathrm{~m}$, as indicated by TC 3 and 4 . In TC 3 , organic material appeared to tail off toward the base of the core at almost $5 \mathrm{~m}$. In cores TC 1 and 2, it is likely that sedimentation rates are extremely low due to the small catchment of the Afon Piliau, which does not carry very much sediment (most rivers/ streams 
draining British upland environments are supply-limited for sediment due to hard-rock lithology, moderate rainfall and/or dense vegetation cover; Newson and Large, 2006). Active sedimentation is currently limited to organic accumulation and is restricted to the northern portions of the marsh. Radiocarbon dating of core TC4 indicates that organic accumulation has occurred in the Rosehill Marsh for at least the last 4500 years (Table 1) at an average accretion rate of 0.87 $\mathrm{mm} \cdot \mathrm{yr}^{-1}$.

In core TC1, the sedimentary sequence fines toward the top, suggesting reducing sediment availability from the catchment of the Afon Piliau. In contrast, cores TC2 and TC3 there is a slight upward coarsening trend, suggesting occasional sediment inputs from the Teifi River in the past.

\subsubsection{Benthic invertebrate community in the Teifi Estuary}

The benthic invertebrate fauna along the Teifi Estuary changes significantly from an impoverished, species poor estuarine benthic community (B3 and B4) to one increasingly dominated by freshwater species (B5). Environmental conditions changed with increasing distance from the mouth of the estuary. Salinity was significantly correlated with distance $\left(\mathrm{R}^{2}=-0.85\right)$ and decreased from 13.45 at B1 b 1 at sites 3, 4 and 5 (Fig. 1). Surface water temperature decreased from 15.4 at $\mathrm{B} 1$ to $14.5{ }^{\circ} \mathrm{C}$ at $\mathrm{B} 5$. Surface sediments fined up the river, with over $80 \%$ silt and clay at $\mathrm{B}_{3}$ to $\mathrm{B}_{5}$, compared to $66 \%$ and $13 \%$ at sites $\mathrm{B}_{1}$ and $\mathrm{B} 2$.

There was a significant difference between the benthic infauna community structure at all sites along the Teifi estuary and river, with the exception of sites 3 and 4 (Fig. 5; PERMANOVA Pseudo-F $=16.1, \mathrm{P}=0.0001$; pair-wise test all $\mathrm{P} \mathrm{b} 0.05$ except comparison groups 3,4 with $\mathrm{P}=0.078$ ). The similarity of samples within sites was greatest at B1 with 90.2 and decreased to 59.9 at B5. This suggests an increasing spatial patchiness in the benthic community upriver.

Ninety-two point eight \% of the variation in the community structure between sites could be explained by the predictor variables 'distance from mouth of estuary', '\% sand' and '\% clay and silt' (DistLM). The model was visualised by dbRDA where axes 1 and 2 explained 99.6\% of the variation of the fitted model and 92.4\% out of the total variation (Fig. 5). 'Distance from the mouth of the estuary' alone explained $51 \%$ or the variation (DistLM, forward selection, Pseudo-F 3.1, P = 0.04).

\begin{tabular}{|c|c|c|c|c|c|c|c|}
\hline Laboratory sample name & Field sample name & Material & Depth $(\mathrm{cm})$ & Measured age & $13 \mathrm{C} / 12 \mathrm{C}$ & Conventional age & 2 sigma calibration \\
\hline Beta-332678 & TC4-49 & Peat & $106-108$ & $980 \pm 30 \mathrm{BP}$ & $-26.2 \mathrm{o} / 00$ & $960 \pm 30 \mathrm{BP}$ & Cal 1020 CE to 1160 (Cal BP 930 to 790 ) \\
\hline Beta-332679 & TC4-96 & Peat & $200-202$ & $1320 \pm 30 \mathrm{BP}$ & $-27.3 \mathrm{o} / \mathrm{oo}$ & $1280 \pm 30 \mathrm{BP}$ & Cal 660 CE to 780 (Cal BP 1290 to 1170 ) \\
\hline Beta-332680 & TC4-155 & Peat & $345-350$ & $4000 \pm 30 \mathrm{BP}$ & $-24.5 \mathrm{o} / \mathrm{oo}$ & $4010 \pm 30 \mathrm{BP}$ & Cal 2580 BCE to 2470 (Cal BP 4530 to 4420 ) \\
\hline
\end{tabular}


Species richness was low with $4.3 \pm 0.5$ species $0.01 \mathrm{~m}^{-2}$ (mean \pm sd) at the mouth of the estuary and an average of $\leq 3$ species $0.01 \mathrm{~m}^{-2}$ at all intertidal mudflats bordering the Teifi Marsh. B1 at the mouth of the estuary was characterised by the mud-shrimp Corophium volutator, occurring in densities of $137 \pm 58$ individuals $0.01 \mathrm{~m}^{-2}$ (mean $\pm \mathrm{sd}$ ), reduced to $50 \pm 33$ individuals 0.01 $\mathbf{m}^{-2}$ (mean \pm sd) at B2 and absent from the all other sites. Similarly, the spionid polychaete Streblospio benedicti was present at B1 and 2 with densities of $5.0 \pm 3.0$ and $0.8 \pm 1.3$ ind. $0.01 \mathrm{~m}^{-2}$ respectively, but absent at sites further up the river. Two species occurred at almost all sites: the marine and estuarine polychaete Hediste diversicolor and the freshwater oligochaete Limnodrilus hoffmeisteri. Densities of H.diversicolor decreased from $28.8 \pm 8.3$ ind. $0.01 \mathrm{~m}^{-}$ 2 at $\mathrm{B} 1$ to $3.0 \pm 2.2$ ind. $0.01 \mathrm{~m}^{-2}$ at $\mathrm{B} 4$, and was absent at $\mathrm{B} 5$. In contrast densities of L.hoffmeisteri more than doubled from $43.2 \pm 14.1$ ind. $0.01 \mathrm{~m}^{-2}$ at $\mathrm{B} 1$ to $102.2 \pm 57.0$ ind. $0.01 \mathrm{~m}^{-2}$ at $\mathrm{B}_{5}$. In addition to the freshwater oligochaete, B5 was characterised by insect larvae of mosquitos (Aedes sp. 18.5 \pm 16.9 ind. $0.01 \mathrm{~m}^{-2}$ ) and diptera (Chironomid sp. $12.0 \pm 19.4$ ind. $0.01 \mathrm{~m}^{-2}$ ). Two larvae, ammocoetes, of the lamprey Lampetra fluviatilis were also found in the sediment samples.

\subsection{The present: current relationship between wetland vegetation, benthic communities, hydrology and geomorphology} 3.2.1 Salinity and moisture gradients and plant communities

Salt and moisture tolerance indices developed from vegetation data were considered a more reliable estimate of long term salinity fluctuation than conductivity measurements of ground- and surface water taken during the field visit. These measurements were highly variable, probably because of the impact of recent rainfall and differences in soil porosity. In the absence of a long-term monitoring study, salinity and moisture tolerances for each plot were used to interpolate a trend across the Teifi Marsh (Fig. 6). Interpolation of any kind is not ideal, as it does not take into account controls other than distance between positions and the variable's value at that position. Nevertheless, Fig. 6 does provide a useful indication of salinity and moisture gradients across the wetland.

Assuming vegetation salt tolerance is an indicator of salinity encountered at each position, it is apparent that salinity decreases with distance from the Teifi River. More surprisingly, it is clear from the plot that salt water does occasionally intrude up the Afon Piliau during high tides, and that low-lying areas around the lower Afon Piliau have more salt tolerant vegetation than portions of the Pentood Marsh upstream, which is a palustrine system. In Rosehill Marsh, sites located close to the tidal creek also experience more saline conditions although the intrusion of salt water is limited in extent. This suggests that although Rosehill Marsh is tidal, it is not necessarily saline. Intrusions of concentrated sea water are 
probably infrequent, requiring a combination of low river flows and extraordinarily high tides.

The wettest areas of the wetland are those that experience back flooding from the Teifi River, such as the upper tidal creeks of Rosehill Marsh. The lower western portions of the Pentood Marsh are also extremely wet as sub-surface flow is impounded by the railway embankment. Moisture indices are related to elevation $\left(\mathrm{R}^{2}=0.346 \mathrm{P} \mathrm{b}\right.$ 0.05) as would be expected. Lower elevations are closer to the geomorphic base level set by sea level and the Teifi River, and these elevations are most likely to be flooded either by impoundment or variation in sea and/or river level.

Communities 43, 85 and 7 are associated with high moisture and salinity levels. All are geographically connected to the Teifi River, either via tidal creeks, the Afon Piliau, or are next to the river. Communities 4 and 13 represent the other end of the scale - these communities consist primarily of species that are not salt tolerant and experience lower levels of inundation being located in upstream environments, typically at the break of slope between hill and valley. There is a range of environments between the two that all experience high levels of inundation, as indicated by soil type and vegetation moisture tolerance, but salt tolerance is typically low. This includes communities 24, 11,84, 20 and 25. These communities are frequently the most diverse in terms of vegetation species, and create a patchwork of varied habitat in a relatively small space.
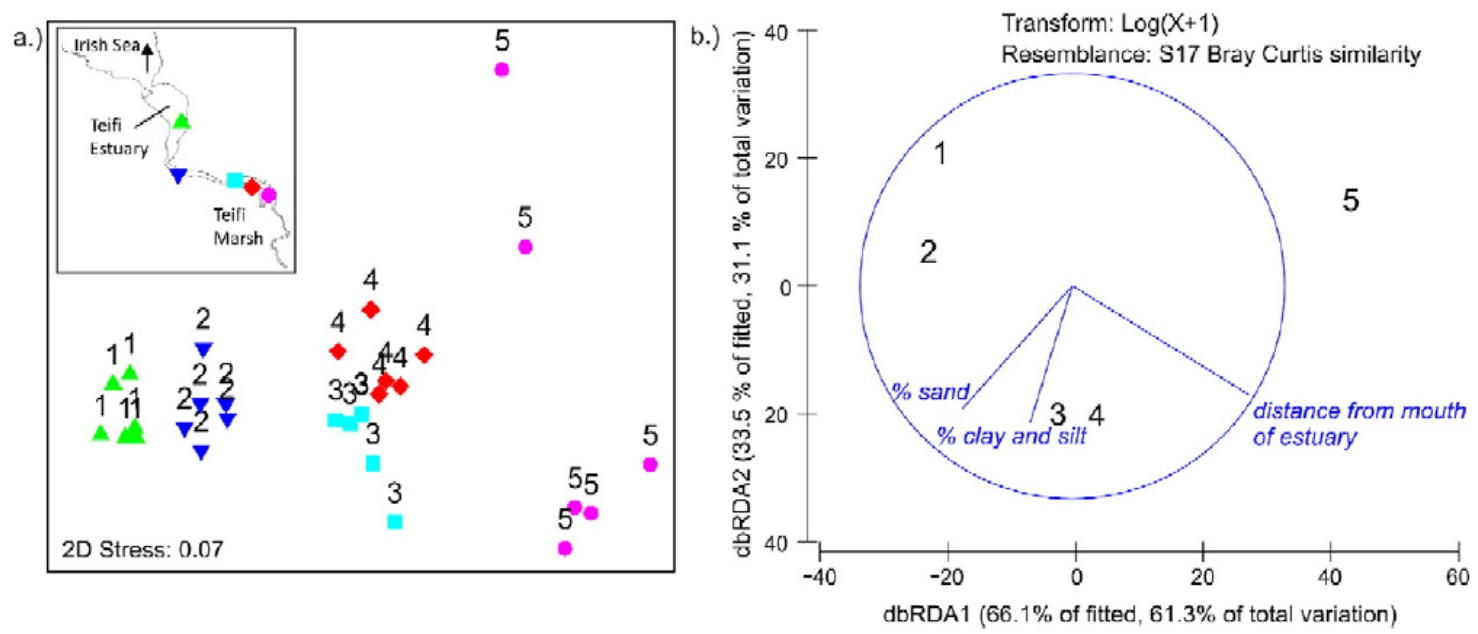

Fig. 5. (a) Similarities of the benthic infauna community structure from the Teifi estuary to the Teifi Marsh 4 km upstream. MDS ordination of Bray-Curtis similarity; comparison of five sampling positions $\left(100 \mathrm{~cm}^{2}\right.$ core samples, $\mathrm{n}=6$ ). (b) Relationship between Teifi benthic community and environmental predictor variables. Distance-based redundancy analysis (dbRDA) ordination for the fitted distance-based linear model (DISTLM) based on Bray-Curtis similarities, versus sediment properties and distance from Teifi estuary. 

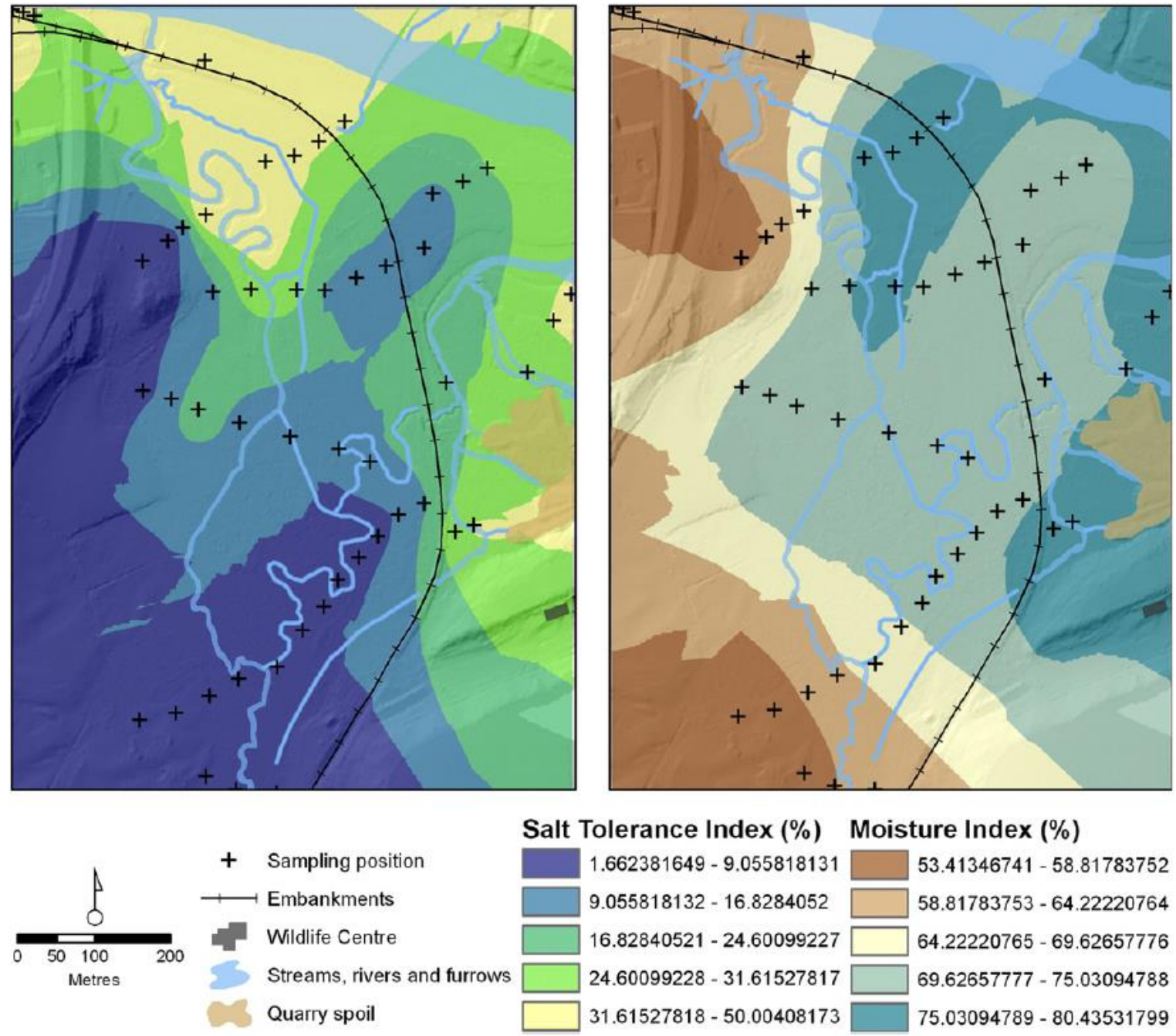

Fig. 6. Kriged interpolation of salt tolerance and moisture tolerance indices for vegetation plots.

These vegetation types are clustered toward the southern end of Pentood Marsh.

The mechanism of separation of salt tolerant and freshwater species in space has been described by Crain et al. (2004). Freshwater plants typically cannot grow in more saline environments, and are limited by physical factors. Contrastingly, salt tolerant plants frequently grow better in freshwater environments, but struggle to compete with freshwater plants for space and nutrients. They are excluded from freshwater environments by biotic rather than physical factors. To achieve a shift in plant communities in an estuarine marsh, salinity and would have to reach toxic levels for freshwater plants, allowing the inland expansion of salt tolerant communities.

However, Dunton et al. (2001) have shown that small inter-annual shifts in vegetation communities may occur due to variation in rainfall. An increase in rainfall can lead to an increase in less salt tolerant species at the expense of more salt tolerant species. Contrastingly, prolonged dry spells may have the opposite effect. 


\subsubsection{Peat formation and the growth of reed beds}

The primary peat former in the Teifi Marshes is P. australis, and as confirmed by dated peat deposits and plant fossils in Rosehill Marsh, it has been for the last 4000 years. However, the extent of peat formation has changed in the last few centuries. Rosehill Marsh has substantial peat deposits. In contrast, deposits in the Pentood Marsh are limited to a maximum of $0.50 \mathrm{~m}$, whereas depths of $\sim 0.20$ $\mathrm{m}$ are the norm. Assuming a constant rate of accumulation across the marshes, peat deposits in Pentood Marsh are b 250 years old. This suggests that the formation of reed beds in this portion of the wetland is relatively recent, and that prior to this, reeds were limited to the adjacent Rosehill Marsh.

An expansion of $\mathrm{P}$. australis in tidal wetlands has been described across the northern hemisphere. Chambers et al. (1999) report that the relative abundance of the species in tidal wetlands of North America has changed dramatically over the last 200 years. In marshes surrounding Chesapeake Bay, an overall increase in the species was mapped over the last century (Rice et al., 2000). One of the major concerns with expansion of P. australis reed beds, is that biodiversity is frequently reduced as assemblages of native plants are replaced (Chambers et al., 1999). However, it has been shown that ecosystem service provision (e.g. prevention of soil erosion, enhancement of water quality and support of higher trophic levels) does not decline if tidal flooding regimes are maintained.

Several reasons have been proposed for the sudden expansion of P. australis at the expense of other species, but the most likely cause in the UK is a change in environmental conditions to ones that are more conducive to growth. Where water flow is unimpeded, P. australis is usually restricted to the high marsh or upland fringe in tidal wetlands as it is limited by various environmental stressors (Chambers et al., 1999, Clevering, 1997). When the effect of salinity and sulphides is reduced, it may become extensive throughout brackish wetlands. According to Chambers et al. (2003), the invasion and spread of P. australis by seed germination and growth from rhizome fragments is limited to areas where salinity is $\mathrm{b} 10 \%$, sulphide concentrations are below $0.1 \mathrm{mM}$ and flooding frequency is $\mathrm{b} 10 \%$. Thus, $\mathrm{P}$. australis reed beds, although tolerant of salt water, will eventually die back if salinities increase to marine levels. However, they are more tolerant of rising salinity levels than many of the marsh plants present toward the head of Pentood Marsh. Furthermore, P. australis is more tolerant of varying water levels. Meyerson et al. (2000) found that stem density of $\mathrm{P}$. australis was higher in tidal than non-tidal settings, irrespective of water salinity.

Chambers et al. (2003) speculated that one of the main reasons for the broadscale expansion of $\mathrm{P}$. australis in tidal wetlands could be related to nutrient supply. While P. australis is a poor competitor for below ground nutrients in saline 
environments, it as an aggressive coloniser that may successfully out-compete other native plants if the wetland is not nutrient limited.

In the absence of mineral soil accretion in the Teifi marshes, the formation and preservation of peat is the most important geomorphic process currently taking place. Ongoing peat accumulation creates topography, and over time, peat beds become elevated above the water table. The frequency of ruderal species and the apparent dryness of the wetland surface in Rosehill Marsh suggest that the wetland is currently elevated above the water table. If desiccation becomes severe, the peatland surface may be naturally lowered by fire (i.e. burning of the peat), by oxidation (aerobic digestion of organic material) or by compression. Over centuries there may be a natural cycle of peat accumulation to lift the wetland out of the water table, desiccation, lowering of the peat surface, followed by conditions once again becoming suitable for peat formation.

In a scenario where the water table is constantly raised, such as in a tidal wetland where sea level is rising, this cyclical process is likely to be stunted. Instead, ongoing sea level rise will keep the peatland moist and the accretion of organic sediment may be permanent. As Kirwan et al. (2010) suggest, the effect of inundation on plant growth and organic accretion may allow marshes to survive conservative projections of sea level rise. At low rates of sea-level rise, organic accretion can maintain peatland elevation relative to sea level, preventing complete inundation.

\subsubsection{Benthic invertebrate community in the Teifi Estuary}

The benthic invertebrate fauna along the Teifi Estuary showed a typical change in composition adapting to a salinity gradient from brackish waters to a freshwater community further up the river (McLusky et al., 1993).

Both salinity and temperature correlated significantly with distance from the mouth of the estuary, and it was not possible to disentangle which of the factors, or their interaction, drove the change in the benthic community. However, the nature of the species contributing to the change suggests that salinity was the most important factor: species such as the mud-shrimp C. volutator and the spionid S. benedicti typically occur in marine and estuarine conditions, while insect larvae indicate freshwater conditions. The results suggest that the tidal mudflats bordering the Teifi Marsh currently represent the transition zone from a fringe estuarine community to a fully freshwater driven ecosystem. The zone was species-poor with the oligochaete L. hoffmeisteri being by far the most common species. The ecological importance of the area is heightened by confirming the presence of lamprey larvae ammocoetes in the mud flats. The sampling method was not appropriate for assessing the abundance of ammocoetes, and their numbers in the tidal mudflats of the Teifi River were certainly underestimated. Lampreys are protected under the EC Habitats Directive (1992) and their presence indicates that 
the mudflats bordering the Teifi Marsh may be a breeding area for the species (Goodwin et al., 2008).

\section{Discussion: how might the Teifi estuary wetlands change as sea levels rise? 4.1 Forecast levels of inundation and peat formation through model simulations}

In all simulations, the extent of peat formation increased with rising sea level as a result of the slope of the Teifi Marshes relative to the water table (Figs. 7-9). The simulations suggest that carbon sequestration through peat formation will be enhanced for at least the next 200 years. Eventually, water may become too deep and saline for P. australis growth, resulting in localised dieback at the fringe of the Teifi River. This is unlikely to occur within the next 200 years.

Although Kirwan et al. (2010) suggested that peat accumulation could potentially keep up with conservative amounts of sea level rise, this is impossible in the Teifi Marshes. Current rates of sea level estimated from gauges and corrected for isostatic movement, exceed rates of marsh accumulation by over $200 \%$. The averaged rate of peat accretion in Rosehill Marsh is $0.87 \mathrm{~mm} \cdot \mathrm{yr}^{-1}$, while current rates of sea level rise at Newlyn, Fishguard II and Milford Haven are 2.3, 4.1 and $7.3 \mathrm{~mm} \cdot \mathrm{yr}^{-1}$ respectively. Long term projections for sea level rise at Cardiff are between 5 and 7 times the rate of peat accretion.

When sedimentation is dominated by organic accretion, it appears unlikely it can keep up with the pace of sea level rise in any climatic setting. In a similar blockedvalley lake wetland in sub-tropical southern Africa, the rate of organic accumulation is $1.3 \mathrm{~mm} \cdot \mathrm{yr}^{-1}$ (Grenfell et al., 2010). This suggests that even at higher rates of growth due to increased temperature, the Teifi marsh would be vulnerable to even low estimates of sea level rise. Indeed, Kirwan et al. (2008, 2010) conclude that under scenarios of more rapid sea level rise, such as those that include ice sheet modelling, most tidal marshes will likely submerge near the end of the 21st century.

As expected, the extent of flooding at mean sea level up the course of the Teifi River increases as sea level rises. In the low estimate simulation, the upper limit of intrusion at mean sea level migrates upstream by $\sim 250 \mathrm{~m}$ in 200 years. In the high estimate simulation, the same intrusion is achieved in 175 years. Increased flooding is most noticeable in the tidal flats of Rosehill Marsh, but increases in sea level also propagate up the Afon Piliau. In the short term, this will lead to increased flooding of the Pentood Marsh as freshwater from the Afon Piliau becomes impounded.

Model simulations of changes in mean high water neap and spring tides provide an indication of the frequency of inundation. Areas below neap tide level will 
be flooded daily during every flood tide, while areas between the spring and neap flood tide level will be flooded to varying degrees of frequency depending on elevation. However, areas that are inundated during flood tides will not necessarily be flooded by saltwater. Freshwater from the Afon Piliau will be impounded, and the exact nature of mixing of salt- and freshwater will depend on the flow regime of both the Teifi and Piliau rivers.

Changes to the extent of inundation at neap and flood tides may be dramatic as sea level rises (Figs. 10-12). The output from the low estimate sea level rise simulation at 25 years from 2010 is most similar to the current situation. In this simulation, it can be seen that at MHWN, saltwater intrudes only up the deepest portions of the Afon Piliau, and is probably tempered by freshwater flow from the Pentood Marsh. The tidal flats of Rosehill Marsh are usually inundated during neap floods, but the extent is limited to sand flats and creeks within Rosehill Marsh only. Some portions of Rosehill Marsh are not inundated even at MHWS - these areas correspond to vegetation community 20 (Phragmites australis reedbed with terrestrial ruderals), which currently displays signs of desiccation due to elevation above the water table.

In 50-75 years, almost all of Rosehill Marsh is inundated at MHWS (low estimate, Fig. 10). In 125 years, flooding during MHWN extends up the tidal creeks of Rosehill Marsh, under the embankment and into Pentood Marsh for the first time, although this is limited in areal extent. The entire tidal creek area is inundated at MHWN at 150 years. From 175 years, change is rapid and dramatic. Due to the very low slope of the wetland, once an elevation threshold is exceeded, large portions of the wetland become flooded. In low estimate simulations though, most of the wetland is not flooded by every tide.

Simulations using medium estimates of sea level rise produce rapid and dramatic changes. Pentood Marsh becomes susceptible to tidal inundation from the Rosehill creeks in 100 years. The entire tidal creek system of Rosehill Marsh is inundated in 125 years. Between 150 and 175 years, there is a sudden increase in the extent and frequency of flooding. By 200 years, two thirds of the wetland is inundated during every flood tide. 

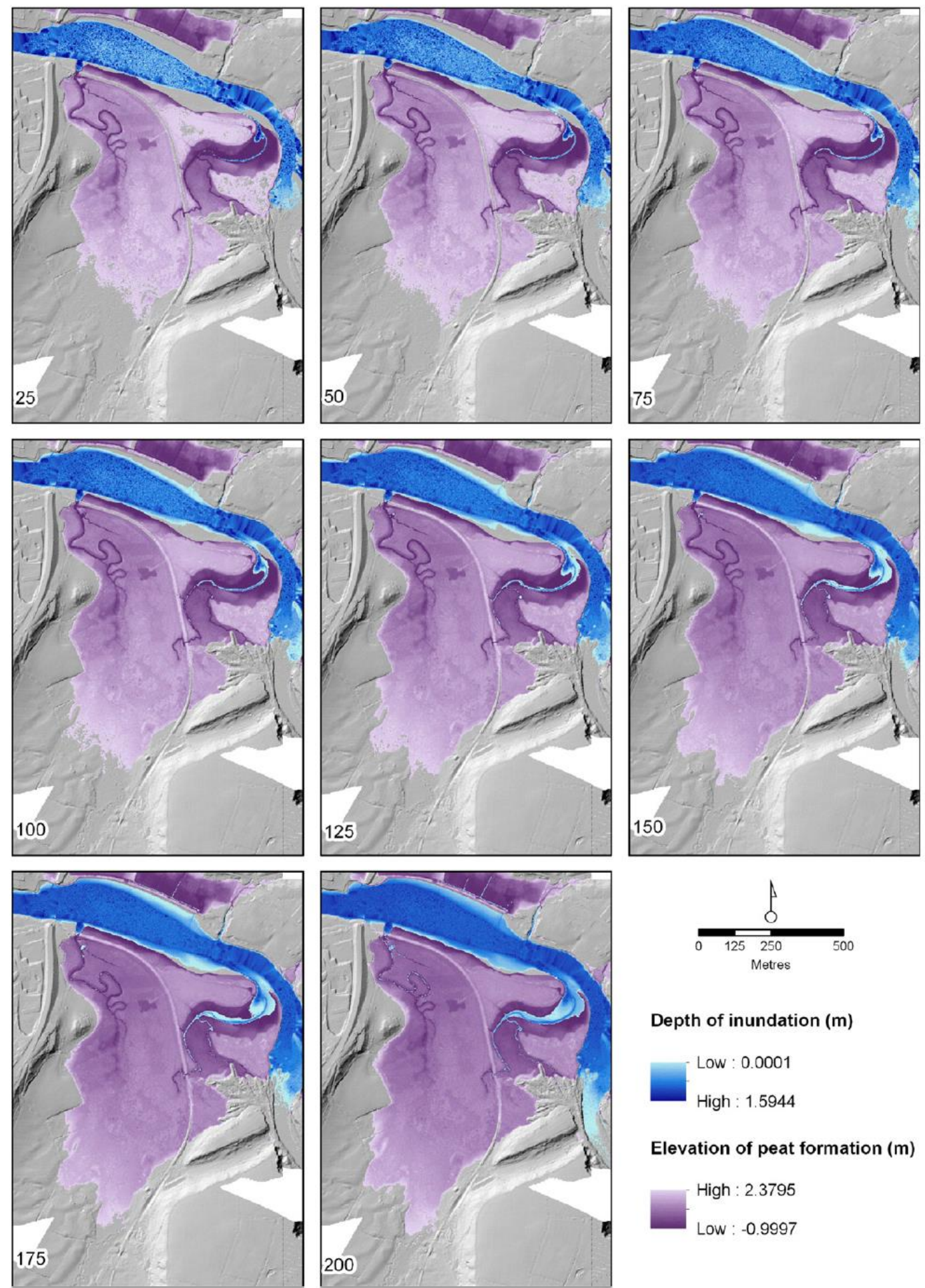

Depth of inundation $(\mathrm{m})$

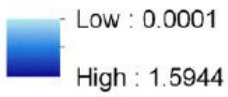

Elevation of peat formation $(\mathrm{m})$

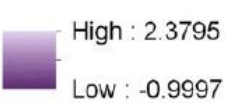

Fig. 7. Inundation by rising sea levels simulated from forecast mean sea level for Cardiff (low estimate). The impact of the changing groundwater table on peat formation is also shown.

At high estimates of sea level rise, the tipping point in sudden increases in flooding is reached between 125 and 150 years. Two thirds of the wetland is always inundated by flood tides in 175 years. 
The simulations suggest an initially slow response to rising sea levels that may be tempered by river flows from the Teifi and Piliau Rivers. However, even in the short term, rising sea level will result in increased inundation as freshwater becomes impounded on the Pentood Marsh. Over time, the extent of saltwater intrusion will undoubtedly increase as every flood tide inundates larger portions of the wetland.

The gradual changes in frequency and extent of inundation at flood tide reaches a tipping point 125 to 175 years from 2010. This occurs because of the extremely low slope of the wetland surface. Once a particular elevation threshold is reached, large portions of the wetland become flooded at every flood tide. At this time, in addition to increased inundation, saltwater intrusion will certainly become more common.

\subsection{Potential impact of sea level rise on the dynamics of the Teifi Marshes}

Plant communities tend to respond quickly to changes in environmental conditions. As sea level rises and the frequency of inundation during flood tides increases, the extent, frequency and magnitude of salt water incursion into the Pentood and Rosehill Marshes will also increase. 

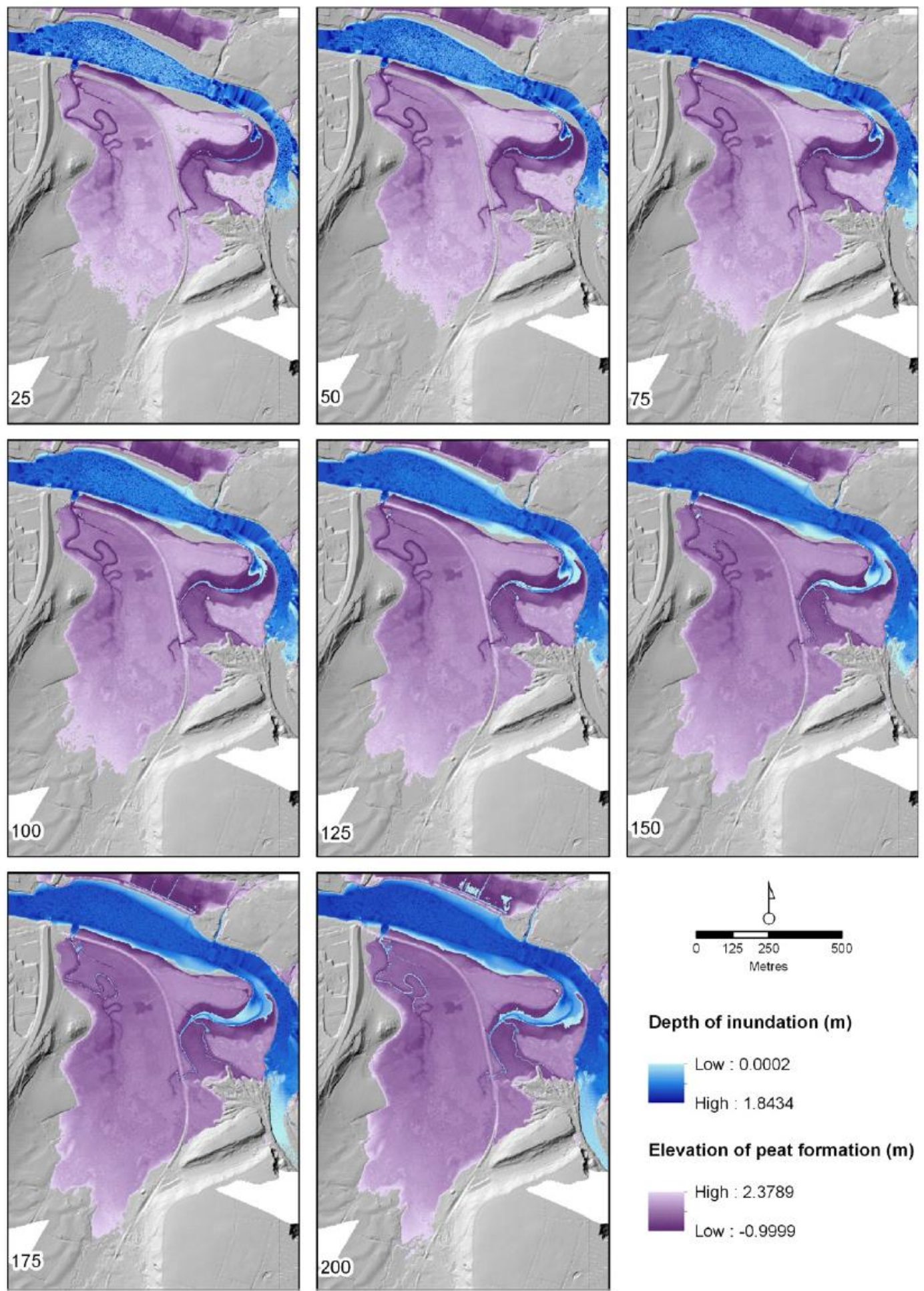

Depth of inundation $(\mathrm{m})$

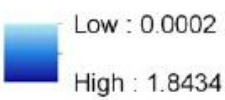

Elevation of peat formation $(\mathrm{m})$

High : 2.3789

Low : -0.9999

Fig. 8. Inundation by rising sea levels simulated from forecast mean sea level for Cardiff (medium estimate). The impact of the changing groundwater table on peat formation is also shown.

The Rosehill Marsh may respond more quickly to sea level rise due to the highly connected nature of its tidal creeks. However, the Pentood Marsh has a greater diversity of communities and plant species, and the changes are likely to be more dramatic than in the relatively monospecific Rosehill Marsh, although their 
vegetation communities' will eventually becoming more similar as their inundation conditions converge.
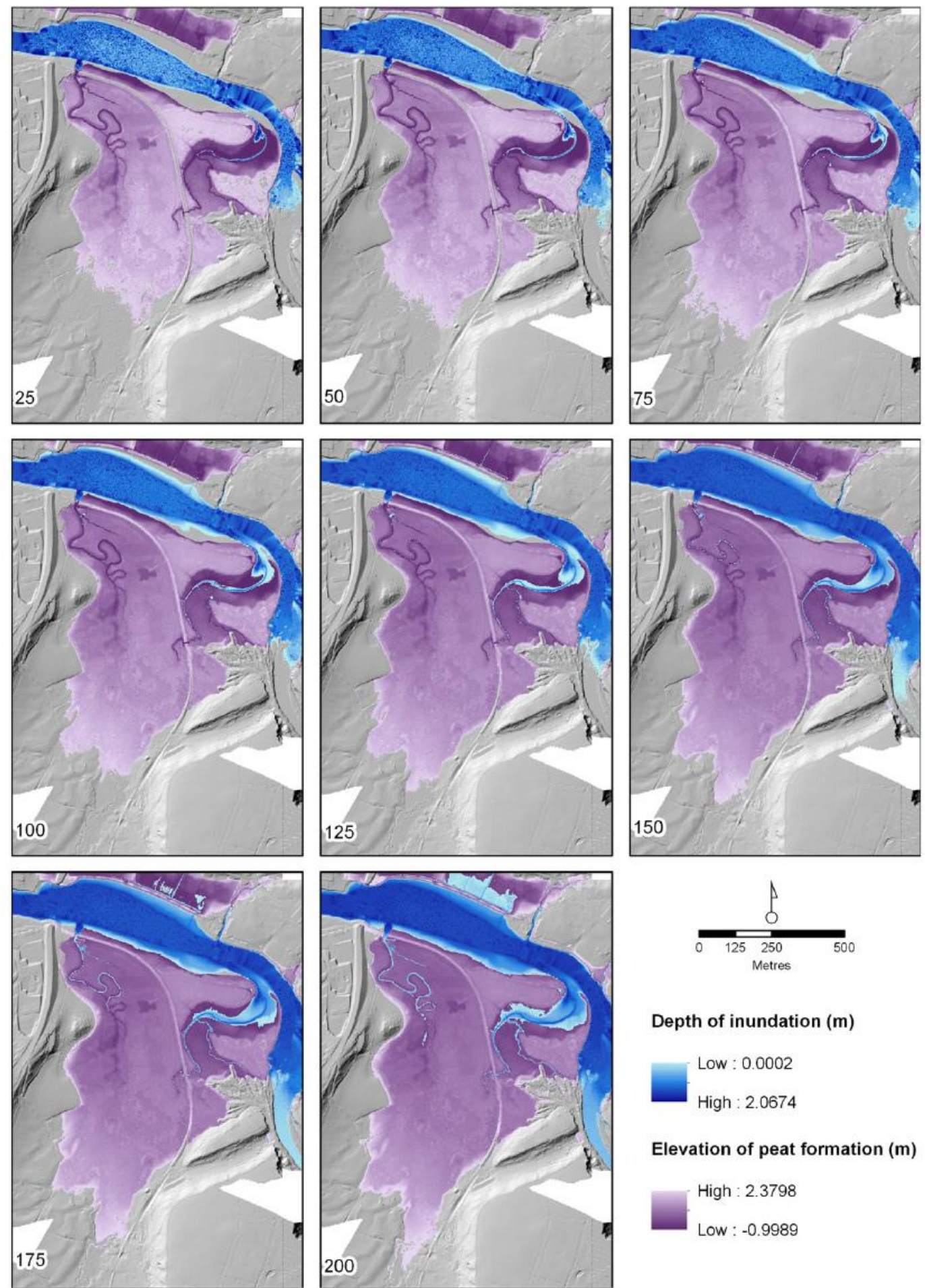

Depth of inundation $(m)$

Low : 0.0002

Elevation of peat formation ( $m)$

High : 2.3798

Low : -0.9989

Fig. 9. Inundation by rising sea levels simulated from forecast mean sea level for Cardiff (high estimate). The impact of the changing groundwater table on peat formation is also shown.

Vegetation communities will shift along a continuum of salt and moisture tolerance as the frequency of salt water intrusion increases. There are two potential pathways along which communities may shift - one dominated by reeds 
and the second characterised by the occurrence of rushes (Fig. 13). Moisture indices suggest that the depth and frequency of inundation could distinguish between the two pathways. However, it is possible that other environmental factors that have not been measured may be important, such as nutrient availability, proximity to flowing water or groundwater seeps or sediment loads in flowing water.
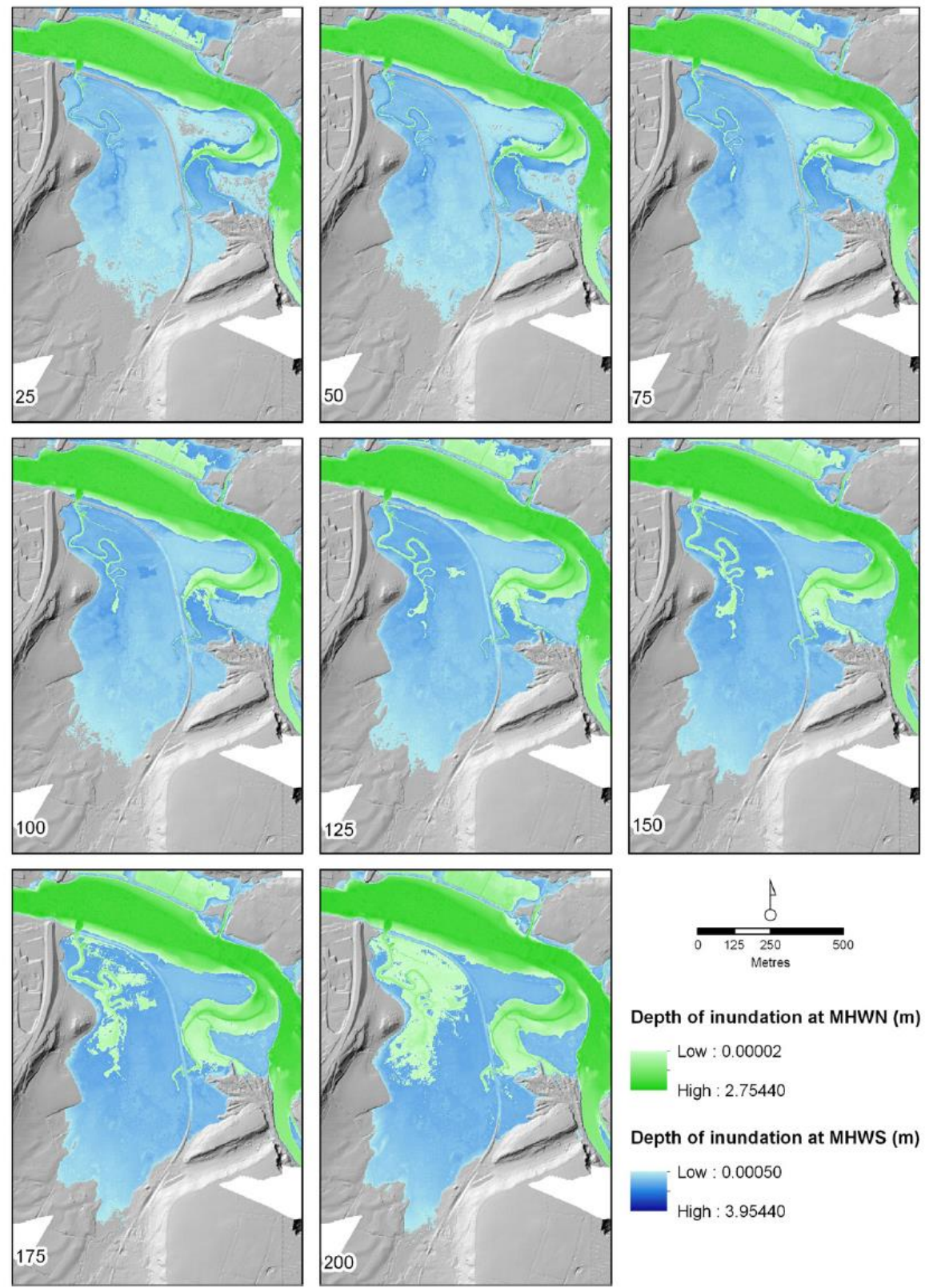

Depth of inundation at MHWN (m)

Low : 0.00002

High : 2.75440

Depth of inundation at MHWS $(\mathrm{m})$

Low : 0.00050

High : 3.95440

Fig. 10. Comparison of Mean High Water Neap (MHWN) and Mean High Water Spring (MHWS) inundation levels based on the forecast mean sea level for Cardiff (low estimate) and current mean high water at Cardigan (Town). 

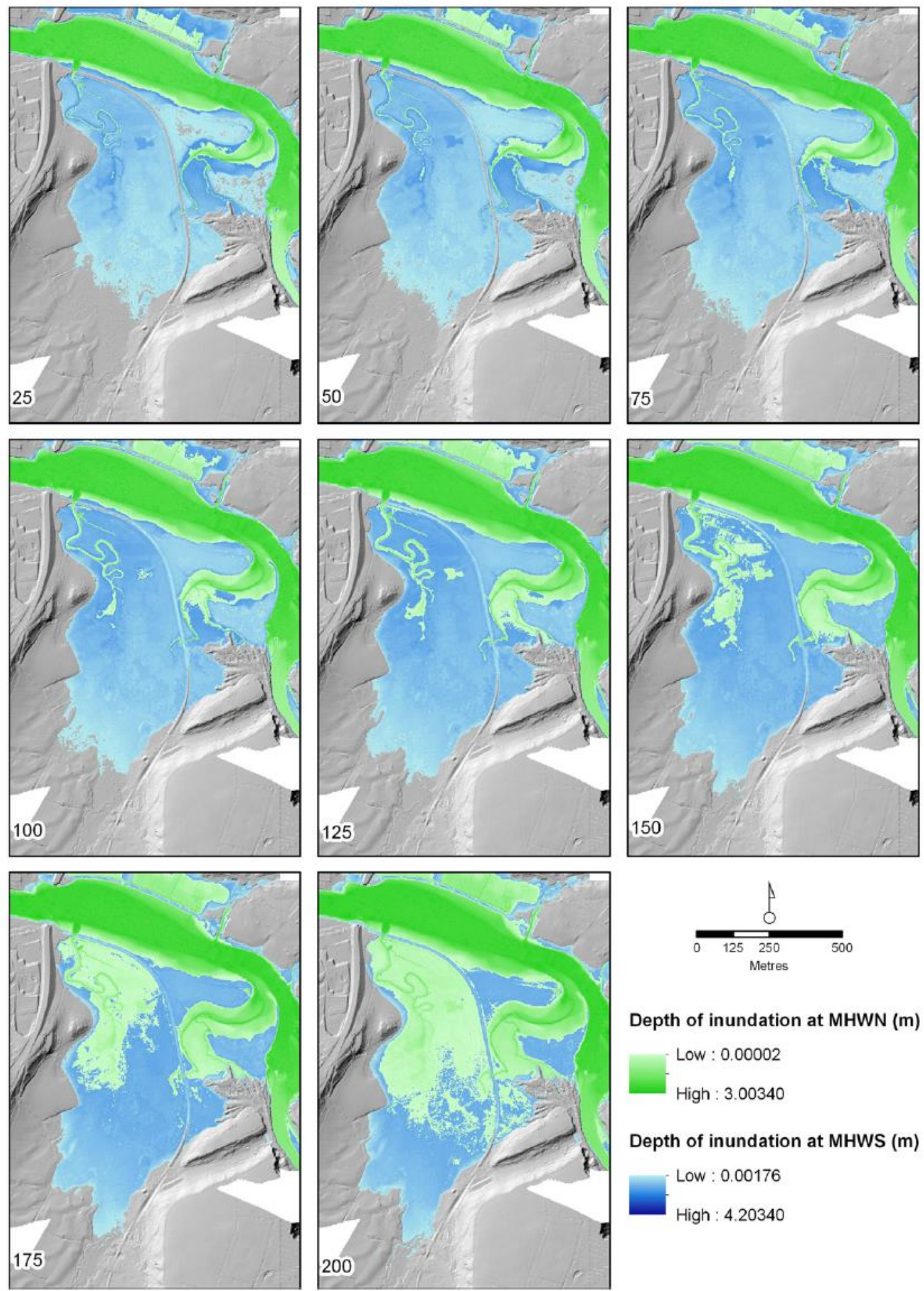

Depth of inundation at MHWN (m)

Low : 0.00002

High : 3.00340

Depth of inundation at MHWS (m)

- Low : 0.00176

High : 4.20340

Fig. 11. Comparison of Mean High Water Neap (MHWN) and Mean High Water Spring (MHWS) inundation levels based on the forecast mean sea level for Cardiff (medium estimate) and current mean high water at Cardigan (Town).

The least wet and least salt tolerant communities, representing the freshwater endpoint of the continuum, are 4 (wet woodland and meadow) and 13 (wet plantain, herb and daisy grassland). The other end of the continuum, the most salt tolerant vegetation community, is represented by community 43 (mixed herb and reed marsh with minor Bolboschoenus maritimus). However, additional 
salt tolerant communities that are currently not represented may occur within the Pentood and Rosehill Marsh as sea level rises.
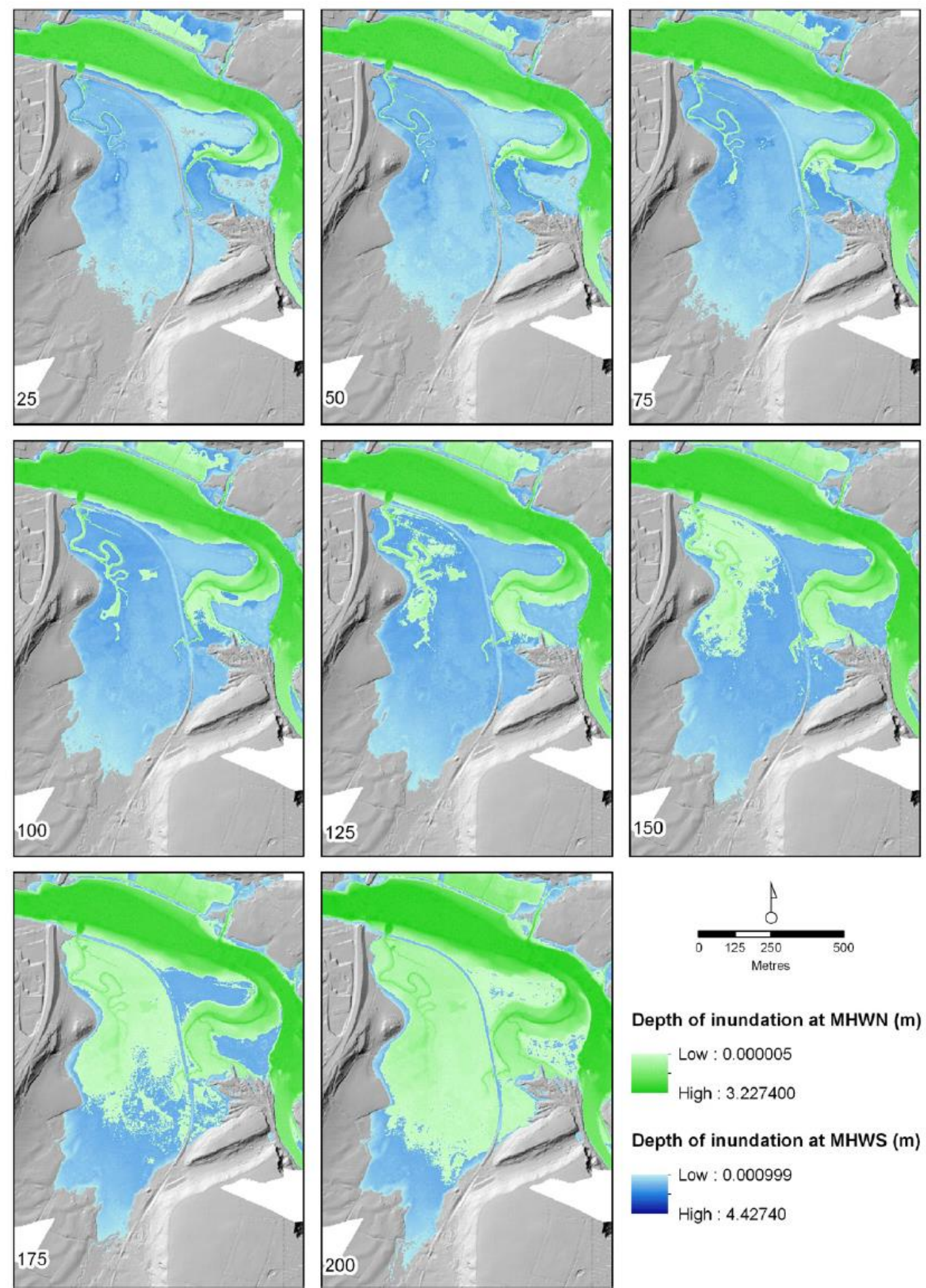

Depth of inundation at MHWN (m)

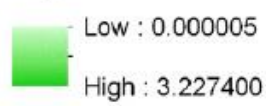

Depth of inundation at MHWS $(\mathrm{m})$

Low : 0.000999

High : 4.42740

Fig. 12. Comparison of Mean High Water Neap (MHWN) and Mean High Water Spring (MHWS) inundation levels based on the forecast mean sea level for Cardiff (high estimate) and current mean high water at Cardigan (Town).

Furthermore, if water becomes too deep during flood tides, it is possible that tidal mudflats may represent the actual maritime end point of the continuum. 
If it is assumed that reed-dominated communities remain reed-dominated as salt exposure increases, vegetation communities could potentially follow a pathway from either 4 or 13, to 11 (Mixed bulrush and reed marsh with herbs), to 84 (Reedbed with creeping herbs), to 20 (Reedbed with terrestrial ruderals), to 85 (Reedbed with nettles on disturbed margins) to 43. If sea levels continue to rise, tidal mudflats may be the endpoint under completely maritime conditions.

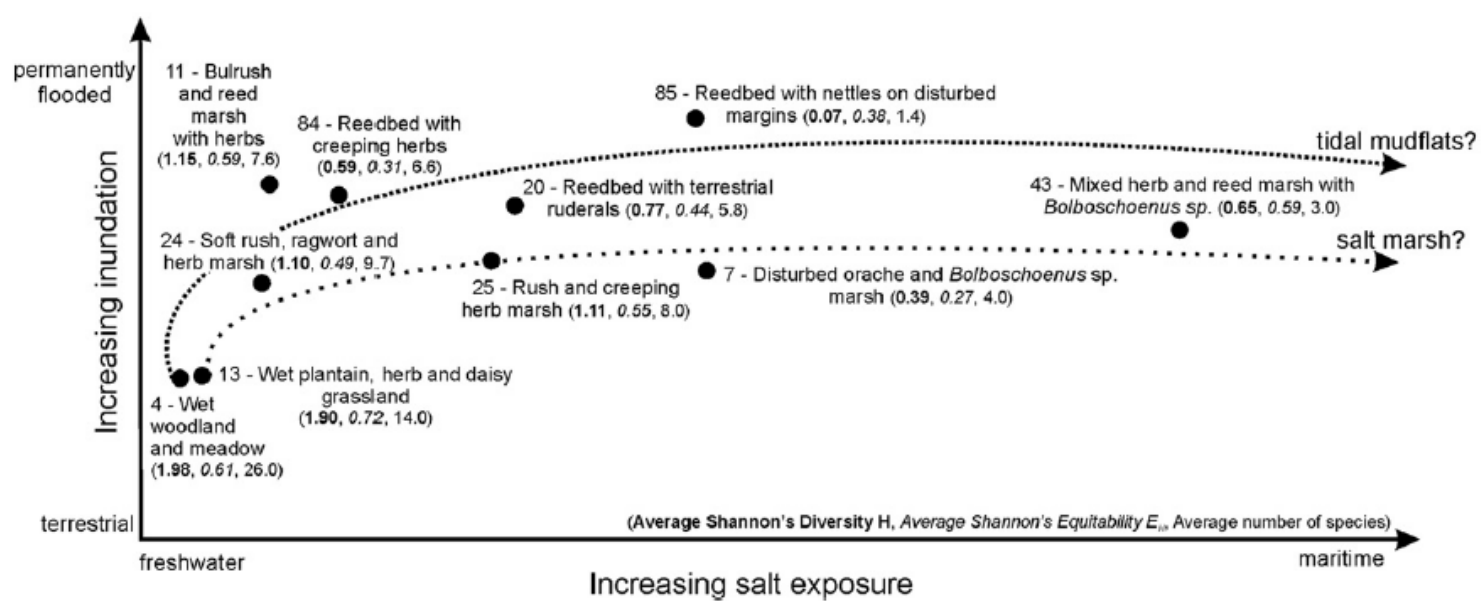

Fig. 13. Potential pathways of vegetation change as exposure to salt water increases. Shannon's Diversity Index (H), a measure of species evenness (EH) and the average number of species in each plot is provided for each community.

An alternative pathway exists, resulting in plant communities without reeds, characterised instead by the presence of rushes. In this case, a vegetation community could change from 4 or 13 , to 24 (soft rush, ragwort and willowherb marsh), to 25 (creeping herb and rush marsh) to 7 (disturbed orache and Bolboschoenus maritimus marsh), and then to 43. In this case, salt marsh communities could potentially represent the end point.

As sea level rises, plants with very low salt tolerances will become necrotic and poor competitors for light, space and nutrients. Plants that can tolerate salt will begin to invade previously diverse freshwater wetland. If a particular species is sufficiently intolerant, replacement could occur even if salt intrusion is initially infrequent. Some scientists have documented inter-annual changes to vegetation communities due to inter-annual variation in run-off and saltwater intrusion, suggesting the change could potentially be rapid (e.g. Dunton et al., 2001).

Fig. 13 further indicates how wetland diversity may be affected. Freshwater communities generally have higher plant diversity, and in addition, individuals of each species tend to be well represented. In contrast, toward the maritime end of the continuum, diversity and equitability decreases. The reedbed communities tend to have lower diversity and equitability than the rush communities at similar positions along the continuum. Ultimately, an increase in sea level will result in a reduction in marsh biodiversity, with plant 
communities switching toward less diverse and occasionally monospecific vegetation communities. This is confirmed by studies which have shown that increases in salinity and flooding reduce seedling emergence even when the seed bank is constant (Baldwin et al., 1996; Petersen and Baldwin, 2004).

In the long term, there will be an expansion of salt tolerant marshes and tidal mudflats at the expense of tidal freshwater marsh. Newly created salt marshes are unlikely to be sustainable due to a lack of sediment supply, and they too will become inundated and convert to tidal mud-flats (Craft et al., 2009). The benthic fauna currently colonising the mud-flats in the estuary suggests that estuarine polychaetes, oligochaetes and amphipods would spread into the freshwater marsh. Tidal mudflats are important feeding grounds for birds and nurseries for juvenile fish, and hence the ecological importance of the area may shift from an extensive freshwater wetland important for rich plant communities and their associated fauna, to an expansive brackish-water mudflat with a productive benthic community providing food and shelter for wading birds and juvenile marine fish.

However, the benthic community composition may change, not necessarily through rising sea levels, but through rising water temperature and the spread of species currently not colonising the area. The species composition may therefore differ from the current fauna, but due to the habitat conditions, i.e. copious food supply from the river, sheltered mudflats, tidal waters, it is plausible that the marsh area will remain productive. The future of individual species such as the lamprey is uncertain. Its nursery ground cannot shift further up the river in tandem with the moving threshold from brackish to freshwater due to the location of the Cenarth gorge immediately upstream.

While the loss of tidal freshwater wetland is in line with global predictions, simulations suggest that in the Teifi marshes the loss will be slower. For instance, Craft et al. (2009) predicted declines in tidal freshwater marsh area of between -2 and $39 \%$ by the year 2100 . Salt marsh was predicted to decline by between 20 and $45 \%$. Craft et al. (2009) also found evidence to suggest that delivery of ecosystem services (e.g. nitrogen accumulation in soil, potential denitrification, etc.) would decline. However, our study shows that at least for one ecosystem service, carbon storage, there is potential for a future increase in the Teifi Marshes.

\section{Conclusion}

In this wetland, rising sea levels will result in an irrevocable change in vegetation communities; it is likely that in the long term, the Teifi Marshes will be less diverse and increasingly dominated by reedbeds and tidal mudflats. While there is potential in this case for more diverse communities to occur further upstream, it is unknown as to whether it is biologically possible within the time scale involved (i.e. $\sim 200$ years). Although they may usually be monospecific, reedbeds allow carbon capture through peat production. Furthermore, both reedbeds and mudflats 
provide valuable habitat for a variety of animals including bird species. Model results suggest that change may be sudden rather than gradual due to the elevation properties of the site. In about 150 years, there is a sudden jump in the proportion of the wetland that is inundated by every flood tide (Fig. 11). Rising sea levels associated with climate change will almost certainly result in a loss of biodiversity in the Teifi Marshes, although changes may not be visible in the next century.

\section{Acknowledgments}

This research was requested by the Wildlife Trust of South and West Wales, and we were assisted in the field by Lizzie Wilberforce and Nathan Walton. SG, RC, AM, CB and IT were supported by SEACAMS, a project part-funded by the European Regional Development Fund through the Welsh Government.

\section{Appendix A. Supplementary data}

Supplementary data associated with this article can be found in the online version, at http://dx.doi.org/10.1016/j.scitotenv.2016.02.196. These data include the Google map of the most important areas described in this article. 


\section{References}

Allen, A., 1960. Seismic refraction investigations of the preglacial valley of the River Teifi near Cardigan. Geolog Magazine 97, 276-282.

Anderson, M.J., Gorley, R.N., Clarke, K.R., 2008. PERMANOVA+ for PRIMER: Guide to Soft- ware and Statistical Methods. PRIMER-E, Plymouth, UK.

van Wijnen, H.J., Bakker, J.P., 2001. Long-term surface elevation change in salt marshes: a prediction of marsh response to future sea-level rise. Estuar. Coast. Shelf Sci. 52, 381-390.

Baldwin, A.H., McKee, K.L., Mendelssohn, I.A., 1996. The influence of vegetation, salinity, and inundation on seed banks of oligohaline coastal marshes. Am. J. Bot. 83, 470-479.

Bradley, S., Milne, G.A., Teferle, F.N., Bingley, R.M., Orliac, E.J., 2009. Glacial isostatic adjust- ment of the British Isles: new constraints from GPS measurements of crustal motion. Geophys. J. Int. 178, 14-22.

Chambers, R.M., Meyerson, L.A., Saltonstall, K., 1999. Expansion of Phragmites australis into tidal wetlands of North America. Aquat. Bot. 64, 261-273.

Chambers, R.M., Osgood, D.T., Bart, D.J., Montalto, F., 2003. Phragmites australis invasion and expansion in tidal wetlands: interactions among salinity, sulphide and hydrolo- gy. Estuaries 26 (2B), 398-406.

Clarke, K.R., Warwick, R.M., 2001. Changes in Marine Communities: An Approach to Sta- tistical Analysis and Interpretation. second ed. PRIMERE, Plymouth.

Clevering, O., 1997. Effects of litter accumulation and water table on morphology and pro- ductivity of Phragmites australis. Wetl. Ecol. Manag. 5, 275-287.

Craft, C., Clough, J., Ehman, J., Joye, S., Park, R., Pennings, S., Guo, H., Machmuller, M., 2009. Forecasting the effects of accelerated sea-level rise on tidal marsh ecosystem services. Front. Ecol. Environ. 7, 73-78.

Crain, C.M., Silliman, B.R., Bertness, S.L., Bertness, M.D., 2004. Physical and biotic drivers of plant distribution across estuarine salinity gradients. Ecol 85 (9), 2539-2549.

Day, J., Rybczyk, J., Scarton, F., Rismondo, A., Are, D., Cecconi, G., 1999. Soil accretionary dy- namics, sea-level rise and the survival of wetlands in Venice lagoon: a field and modelling approach. Estuar. Coast. Shelf Sci. 49, 607-628.

Day, J.W., Christian, R.R., Boesch, D.M., Yáñez-Arancibia, A., Morris, J., Twilley, R.R., Naylor, L., Schaffner, L., Stevenson, C., 2008. Consequences of climate change on the ecogeomorphology of coastal wetlands. Estuar Coast 31, 477-491.

Dunton, K., Hardegree, B., Whitledge, T., 2001. Response of estuarine marsh vegetation to interannual variations in precipitation. Estuar Coast 24, 851-861.

Edmonds, D.A., 2012. Restoration sedimentology. Nat. Geosci. 5, 758-759.

FitzGerald, D., Fenster, M.S., Argow, B.A., Buynevich, I.V., 2008. Coastal impacts due to sea- level rise. Annu. Rev. Earth Planet. Sci. 36, 601-647. 
Fletcher, C.J.N., Siddle, H.J., 1998. Development of glacial Llyn Teifi, west Wales: evidence for lake-level fluctuations at the margins of the Irish Sea ice sheet. J Geolog Soc 155, 389-399.

Glasser, N.F., Etienne, J.L., Hambrey, M.J., Davies, J.R., Waters, R.A., Wilby, P.P., 2004. Glacial meltwater erosion and sedimentation as evidence for multiple glaciations in west Wales. Boreas 33, 224-237.

Goodwin, C.E., Dick, J.T.A., Rogowski, D.L., Elwood, R.W., 2008. Lamprey (Lampetra fluviatilis and Lampetra planeri) ammocoete habitat associations at regional, catch- ment and microhabitat scales in Northern Ireland. Ecol. Freshw. Fish 17 (4), 542-553.

Goor, M.A.V., Zitman, T.J., Wang, Z.B., Stive, M.J.F., 2003. Impact of sea-level rise on the morphological equilibrium state of tidal inlets. Mar. Geol. 202, 211-227.

Grenfell, S.E., Ellery, W.N., Grenfell, M.C., Ramsay, L.F., Flügel, T.J., 2010. Sedimentary facies and geomorphic evolution of a blocked-valley lake: Lake Futululu, northern Kwazulu- Natal, South Africa. Sedimentology 57, 11591174 .

Haslam, S.M., 1972. Phragmites communis Trin. (Arundo phragmites L.,? Phragmites australis (Cav.) Trin. Ex Steudel). J. Ecol. 6o (2), 585-610.

Hill, M.O., Šmilauer, P., 2005. WinTWINS Version 2.3. TWINSPAN for Windows Version 2.3. Centre for Ecology \& Hydrology, Huntingdon and University of South Bohemia, České Budějovice.

Online Atlas of the British and Irish Flora, 2013. Jointly Managed by the Botanical Society of the British Isles. Biological Records Centre, Joint Nature Conservation Committee and Centre for Ecology and Hydrology. http://www.brc.ac.uk/plantatlas/ Accessed January 2013.

Jongman, R.H.G., Ter Braak, C.J.F., van Tongeren, O.F.R., 1995. Data Analysis in Community and Landscape Ecology. Cambridge University Press, Cambridge.

Kirwan, M., Temmerman, S., 2009. Coastal marsh response to historical and future sea-level acceleration. Quat. Sci. Rev. 28, 1801-1808.

Kirwan, M., Murray, A., Boyd, W., 2008. Temporary vegetation disturbance as an explana- tion for permanent loss of tidal wetlands. Geophys. Res. Lett. 35. http://dx.doi.org/10. 1029/2007GLo32681.

Kirwan, M.L., Guntenspergen, G.R., D'Alpaos, A., Morris, J.T., Mudd, S.M., Temmerman, S., 2010. Limits on the adaptability of coastal marshes to rising sea level. Geophys. Res. Lett. 37. http://dx.doi.org/10.1029/2010GLO45489.

McLusky, D.S., Hull, S.C., Elliott, M., 1993. Variations in the intertidal and subtidal macro- fauna and sediments along a salinity gradient in the upper Forth Estuary. Neth. J. Sea Res. 27 (2-4), 101-109.

Meyerson, L., Saltonstall, K., Windham, L., Kiviat, E., Findlay, S., 2000. A comparison of Phragmites australis in freshwater and brackish marsh environments in North America. Wetl. Ecol. Manag. 8, 89-103. 
Milne, G.A., Shennan, I., Youngs, B.A.R., Waugh, A.I., Teferle, F.N., Bingley, R.M., Bassett, S., Cuthbert-Brown, C., Bradley, S.L., 2006. Modelling the glacial isostatic adjustment of the UK region. Phil Trans Royal Soc Part A 364, 931-948.

Moorhead, K.K., Brinson, M.M., 1995. Response of wetlands to rising sea level in the lower coastal plain of North Carolina. Ecol. Appl. 5 (1), 261-271.

Morris, J., Sundareshwar, P., Nietch, C., Kjerfve, B., Cahoon, R., 2002. Responses of coastal wetlands to rising sea level. Ecol 83 (10), 2869-2877.

Newson, M.D., Large, A.R.G., 2006. 'Natural' rivers, 'hydromorphological quality' and river restoration: a challenging new agenda for applied fluvial geomorphology. ESP\&L 31, 1606-1624.

Nicholls, R., Hoozemans, F., Marchand, M., 1999. Increasing flood risk and wetland losses due to global sea-level rise: regional and global analyses. Glob. Environ. Chang. 9, S69-S87.

Nittrouer, J.A., Best, J.L., Brantley, C., Cash, R.W., Czapiga, M., Kumar, P., Parker, G., 2012. Mitigating land loss in coastal Louisiana by controlled diversion of Mississippi River sand. Nat. Geosci. 5, 534-537.

Patrick, W., DeLaune, R., 1990. Subsidence, accretion, and sea level rise in south San Francisco Bay marshes. Limnol. Oceanogr. 35 (6), 1389-1395.

Petersen, J.E., Baldwin, A.H., 2004. Seedling emergence from seed banks of tidal freshwa- ter wetlands: response to inundation and sedimentation. Aqua Bot 78, 243-254. Permanent Service for Mean Sea Level (PSMSL), 2013. Tide gauge data. PMSL Database. http://www.psmsl.org/data/obtaining/. Extracted 5 September 2012.

POLTIPS, 2013. Proudman Oceanographic Laboratory Tidal Prediction Software. http:// noc.ac.uk/using-science/productsservices/software/poltips/poltips-3. Accessed March 2013.

Poulter, B., Halpin, P.N., 2008. Raster modelling of coastal flooding from sea-level rise. Int J Geograph Info Sci 22, 167-182.

Priestnall, G., Jaafar, J., Duncan, A., 2000. Extracting urban features from LiDAR digital sur- face models. Comp, Env \& Urb Sys 24, 65-78.

Reed, D.J., 2002. Sea-level rise and coastal marsh sustainability: geological and ecological factors in the Mississippi delta plain. Geomorphol 48, 233-243.

Rice, D., Rooth, J., Stevenson, J., 2000. Colonization and expansion of Phragmites australis in upper Chesapeake Bay tidal marshes. Wetlands 20 (2), 280299.

Rogers, K., Saintilan, N., Copeland, C., 2012. Modelling wetland surface elevation dynamics and its application to forecasting the effect of sea level rise on estuarine wetlands. Ecol. Model. 244, 148-157.

Shennan, I., Bradley, S.L., Milne, G.A., Brooks, A., Bassett, S.E., Hamilton, S., 2006. Relative sea level changes, glacial isostatic modelling and ice-sheet reconstructions from the British Isles since the Last Glacial Maximum. J. Quat. Sci. 21 (6), 585-599. 
Temmerman, S., Govers, G., Wartel, S., Meire, P., 2004. Modelling estuarine variations in tidal marsh sedimentation: response to changing sea level and suspended sediment concentrations. Mar. Geol. 212, 1-19.

UKCIP, 2010. UKCPo9 sea level change estimates. http://www.ukcip.org.uk/wordpress/wp-content/PDFs/UKCIP_sealevel.pdf. Accessed 14 February 2013.

Warren, R.S., Niering, W.A., 1993. Vegetation change on a northeast tidal marsh: interac- tion of sea-level rise and marsh accretion. Ecol 74, 96103.

Woodworth, P.L., Player, R., 2003. The permanent service for mean sea level: an update to the 21st century. J Coastal Res 19, 287-295. 